\title{
COLONIALISMO Y SANTIDAD EN LAS ISLAS MARIANAS: LA SANGRE DE LOS MÁRTIRES (1668-1676)*
}

\author{
POR \\ Alexandre Coello de la Rosa \\ Departament d'Humanitats. Universitat Pompeu Fabra-CSIC \\ alex.coello@upf.edu
}

\begin{abstract}
RESUMEN
En este artículo examino la conquista y colonización de las islas Marianas (1668-1676) como un ejemplo de la construcción de la frontera católica en las posesiones españolas del Pacífico. Uno de los objetivos es analizar el martirio como uno de los mecanismos utilizados por los misioneros jesuitas para convertir las islas Marianas al catolicismo. Los primeros mártires -Diego Luis de San Vítores, Luis de Medina y Sebastián de Monroy, SJ, entre otros- se convirtieron en «héroes insignes» de la Reforma católica que murieron víctimas de los «bárbaros indómitos» en defensa de la fe. El martirio, como anhelo y culminación de la experiencia misionera, transformó aquellos espacios periféricos en puntos de referencia centrales donde acabaría triunfando el dogma cristiano.
\end{abstract}

PALABRAS CLAVE: Jesuitas, martirio, islas Marianas, Filipinas, siglo XVII.

\footnotetext{
* Una versión preliminar de este ensayo fue presentada en las Jornadas sobre «Religión y heterodoxia en el mundo hispánico (siglos XIV-XVIII)». Facultad de Humanidades, Toledo, 19 de noviembre de 2009. Quisiera agradecer a los asistentes a dichas Jornadas por sus comentarios, a María Dolores Elizalde López-Grueso, a Cristóbal Robles así como a los lectores anónimos de Hispania Sacra por sus comentarios. Este trabajo se inscribe en el Grupo de Estudios Internacionales (GEI) del Consejo Superior de Investigaciones Científicas (CSIC), que dirige la doctora Elizalde, y el Grupo de la Universitat Pompeu Fabra (UPF), «Dinámicas Imperiales: Descolonizacion y transiciones imperiales. El imperio colonial Español (1650-1975)», que coordina el profesor Josep Maria Delgado i Ribas.
} 


\title{
COLONIALISM AND HOLINESS IN THE MARIANA ISLANDS: THE BLOOD OF MARTYRS (1668-1676)
}

\begin{abstract}
In this article I analyze the conquest and colonization of the Marianas islands (1668-1676) as an example of the construction of the Catholic frontier in the Spanish possessions in the Pacific. One of the main objectives consists of analyzing martyrdom as one of the strategies used by the Jesuit missionaries to convert the Marianas islands to the Catholic faith. The first Jesuit martyrs -Diego Luis de San Vítores, Luis de Medina, and Sebastián de Monroy, SJ, among others- were elevated to the category of «distinguished heroes» of the Catholic Reformation who died as victims of the unbeatable barbarians in defence of Christian faith. Martyrdom, as longing and culmination of the missionary experience, turned those peripheral spaces into central points of reference wherein would end up rooting Christian dogma.
\end{abstract}

KEY WORDS: Jesuits, martyrdom, Marianas islands, Philippines, $17^{\text {th }}$ century.

Recibido/Received 17-06-2009

Aceptado/Accepted 22-09-2010

El 5 de febrero de 1597, en Nagasaki, murieron veintiséis cristianos, entre ellos los franciscanos Pedro Bautista y cinco hermanos de hábito, los jesuitas japoneses Pablo Miki, Juan Goto y Santiago Kisai, y diecisiete laicos nacidos en Japón. ${ }^{1}$

Diez años antes el emperador Toyotomi Hideyoshi había prohibido el cristianismo, pero se permitió al franciscano fray Pedro Bautista y a sus tres compañeros establecer su misión en Kyoto. ${ }^{2}$ Sin embargo, la llegada forzosa del galeón español «San Felipe» a las costas del Japón, donde embarrancó, cargado de hombres y mercancías, pero también de soldados, cañones y municiones, desencadenó los acontecimientos. El emperador se apoderó del navío y encarceló a los religiosos, a los cuales decidió ejecutar. Ordenó cortarles la oreja izquierda, y tras pasearlos a pie en pleno invierno, expuestos a las vejaciones e insultos del pueblo, los encarceló. Pero su destino era mucho más siniestro. Hideyoshi decidió crucificarlos por persistir en la predicación del evangelio. Así, desnudos en la cruz, atados con cuerdas y cadenas en brazos y piernas y sujetos al madero con argollas de hierro al cuello, fueron puestos en lo alto de una colina,

\footnotetext{
${ }^{1}$ Luis de GuZmán, SJ, Historia de las Misiones que han hecho los religiosos de la Compañía de Jesús para predicar el Santo Evangelio en los Reinos del Japón. Segunda Parte. Alcalá: Viuda de Juan Gracián, 1601, ff. 610-618; Varones Ilustres de la Compañía de Jesús, Tomo I. Misión del Japón. Bilbao, Imprenta del Corazón de Jesús, 1887, 219-235.

${ }^{2}$ Lucio GuTIÉRREZ, Historia de la iglesia en Filipinas. Madrid, Fundación Mapfre América, 1992, 179-181; Jorge CAÑIZAREs-EsguerRa, Católicos y puritanos en la colonización de América. Madrid: Marcial Pons \& Fundación Jorge Juan, 2007, 255-258.
}

Hispania Sacra, LXIII

128, julio-diciembre 2011, 707-745, ISSN: 0018-215-X 
donde pudieron ser vistos a larga distancia, mientras los fieles se apresuraban a llevarse «algo de los vestidos de los santos, que hallaban tendidos por el suelo, como cosa de mucha estimación y precio». 3

La sangre, decía Michel de Certeau, es la metáfora de la gracia. ${ }^{4}$ En las Filipinas, la estela de los primeros mártires del Japón se propagó con rapidez a través de estampas y cartas martiriales. Los jesuitas, como es sabido, utilizaron las artes plásticas para difundir las vidas heroicas de sus misioneros e impulsar así su beatificación y posterior canonización. ${ }^{5}$

Muchos religiosos, como Diego Luis de San Vítores ${ }^{6}$ y Luis de Medina, ${ }^{7}$ quisieron seguir los pasos de aquellos santos mártires que, imitando a Jesucristo, murieron por defender la fe en las misiones orientales. Y no pocos cayeron en Luzón, Mindanao o las Visayas. ${ }^{8}$ A lo largo del siglo XVII muchos jóvenes jesuitas («indípetas») escribieron a Roma para ofrecerse voluntariamente como misioneros a los confines del imperio. ${ }^{9}$

En este contexto de conquista y conversión aparece una mentalidad o ethos martirial como parte de un programa definitorio de la evangelización jesuita de las islas Filipinas ${ }^{10}$. Para conciliar fines religiosos con medios militares los mártires jesuitas fueron elevados a la categoría de «héroes insignes» de la Reforma católica y «colosos entre gigantes» que murieron en defensa de

3 Estos mártires fueron beatificados el 10 de julio de 1627 por Urbano VIII y canonizados por Pío IX el 8 de agosto de 1862 (Varones Ilustres, Tomo I, 219-230).

${ }^{4}$ Citado en Ines G. ŽuPAnov, «The Prophetic and the Miraculous in Portuguese Asia: a Hagiographical View of Colonial Culture», en Sanjay Subrahmanyam (eds.), Sinners and Saints. The Successors of Vasco da Gama, New Delhi: Oxford UP, 1995, 138.

5 Teófanes EgIDO, Javier BurRIEZA SÁnchez \& Manuel Revuelta GonzÁlez (coord.), Los jesuitas en España y en el mundo hispánico. Madrid, Fundación Carolina \& Marcial Pons, 2004, 92-93; Wenceslao SoTO ARTUÑEDO, «Celebraciones por las canonizaciones de jesuitas en el colegio de Málaga en la Edad Moderna», Revista de Historia Moderna. Anales de la Universidad de Alicante 21 (2003) $150-151$.

${ }^{6}$ El padre Diego Luis de San Vítores nació en Burgos el 12 de noviembre de 1627. Entró en la Compañía de Jesús el 25 de julio de 1640. Era graduado y profeso de cuatro votos (2/12/1660) (Archivum Romanum Societatis Iesu (en adelante, ARSI), «Primus Catalogus Anni Personarum Anni 1696». Philippinae Cat. Trien. 1649-1671, Tomo 2-II, f. 351r).

7 El padre Luis de Medina nació en Málaga el 25 de agosto de 1636. Entró en la Compañía en 1656. En 1671 había hecho los votos de escolar (ARSI, «Primus Catalogus Anni Personarum Anni 1671». Philippinae Cat. Trien. 1649-1696, Tomo 2-II, f. 353r).

${ }^{8}$ Varones Ilustres de la Compañía de Jesús, Tomo III. Misiones de Filipinas, México, Canadá y Brasil, Bilbao, Imprenta del Corazón de Jesús, 1889, 161-163; 195-197; 236-274; 281-286; 309-314.

${ }^{9}$ Gian Carlo Ruscioni, Il Desiderio delle Indie. Storie, sogni e fugue di giovani gesuiti italiani. Turín, Eunadi, 2001, 81; 104.

10 Hemos pedido prestado el término de «mentalidad martirial» del trabajo de Manuel BARRIOS AgUILERA \& Valeriano SÁNCHEZ RAMOS, Martirios y mentalidad martirial en las Alpujarras (De la rebelión morisca a las «Actas de Ugíjar»). Granada, Universidad de Granada, 2001. 
la fe. ${ }^{11}$ El martirio, como anhelo y culminación de la experiencia misionera, transformó aquellos espacios periféricos, poblados de «bárbaros indómitos», en referencias centrales para el triunfo del dogma cristiano.

La literatura hagiográfica sobre la evangelización de las islas Marianas ha ensalzado la vocación apostólica y el espíritu de martirio de los primeros jesuitas que llegaron con el padre San Vítores. ${ }^{12}$ El objetivo consistía en informar a sus superiores en Manila, México y Roma y solicitar la apertura de los procesos ordinarios como paso previo para su elevación a los altares (Florencia, 1673; Vidal Figueroa, 1675; García, 1683; Castro, 1723). Para la iglesia colonial, la santidad actuó siempre como la mejor forma de ejemplarizar la conducta de sus misioneros y sus fieles a través de aquellos «héroes morales». ${ }^{13}$ Como han apuntado diversos autores, las cartas de edificación y las reliquias de los mártires sirvieron como propaganda para la renovación del ideal apostólico. ${ }^{14}$ En un mundo hispánico que recelaba de los herejes, reformados e infieles, los jesuitas fueron baluartes de la cristiandad en las fronteras del imperio.

Con todo, pienso que el papel de mártires de la Micronesia no ha sido debidamente analizado por la historiografía moderna. Mientras que algunos investigadores, en su mayoría jesuitas, han considerado la conquista espiritual en clave heroica a través de las figuras de los misioneros y de sus fieles auxiliares, ${ }^{15}$ todavía faltan estudios sobre el papel de los mártires en la conquista y evangelización de las Marianas. Una zona de frontera -o de «zona de contacto», que diría Marie Louis Pratt- donde «colonizadores y colonizados» establecieron unas relaciones

\footnotetext{
${ }^{11}$ Pedro Murillo Velarde, SJ, Historia de la provincia de Filipinas de la Compañía de Jesús. Segunda parte que comprende los progresos de esta provincia desde el año de 1616 hasta el de 1716 (en adelante, Historia). Manila: Imprenta de Nicolás de la Cruz Bagay, 1749, ff. 331r-331v.

12 Francisco Antonio DE CASTRO, SJ, Laureola sacra de la vida, y martirio del Venerable Padre Diego Luis de San Vítores, primer Apóstol de las Islas Marianas. Madrid, Imprenta de Gabriel del Barrio, 1723.

${ }^{13}$ La beatificación de algunos de ellos (San Vítores, 1985; Pedro Calungsod, 2000) no se produjo hasta finales del siglo XX (Vicente M. DíAz, Repositioning the Missionary: The Beatification of Blessed Diego Luis de Sanvitores and Chamorro Cultural History, Tesis Doctoral, University of California Santa Cruz, 1992, 153-199).

${ }_{14}$ José Luis BouZa Álvarez, Religiosidad contrarreformista y cultura simbólica del Barroco, Madrid: CSIC, 1990; Brad S. Gregory, Salvation at Stake. Christian Martyrdom in Early Modern Europe. Cambridge: Harvard UP [1999] 2001, 298-314.

15 Antonio Astrain, SJ, Historia de la Compañía de Jesús en la Asistencia de España. Tomo VI. Madrid, Razón y Fe, 1920; John N. SchumacheR, SJ, «Felipe Sonsón: Seventeenth Century Filipino Jesuit missionary to the Marianas». Landas: Journal of Loyola School of Theology 9 (1995) 266-285; SCHUMACHER, «Blessed Pedro Calungsod, Martyr: An Historian's Comments on His Philippine Background». Philippine Studies 49:3 (2001a) 287-336; SCHUMACHER, «Blessed Pedro Calungsod, Martyr: An Historian's Comments on the Mission in the Marianas». Philippine Studies 49:4 (2001b) 455-487; Resil B. MoJARES, «The Epiphany of Pedro Calungsod, Seventeenth-Century Visayan Martyr», en: Alfred W. McCoY (eds.), Lives at the Margin. Biography of Filipinos. Obscure, Ordinary and Heroic. Quezon City \& Wisconsin-Madison: Ateneo de Manila UP \& Wisconsin Madison UP, 34-61.
} 
asimétricas de dominación y subordinación. ${ }^{16}$ La construcción simbólica de la frontera pasa, según Christophe Giudicelli, por un proceso ideológico que define como salvajes a sus habitantes. Se les niega toda humanidad y capacidad política, situándolos en un estado pre-social opuesto al estado de «policía humana y cristiana». ${ }^{17}$ Este «salvajismo programático» fue un producto literario elaborado por los hagiógrafos jesuitas para amplificar su violencia y barbarie. Ciertamente, morir en defensa de la fe, frente a los gentiles chamorros (o chamurres, según la apelativo otorgado por Andrés de Urdaneta), ${ }^{18} \mathrm{o}$ frente a los herejes ingleses u holandeses constituía una forma gloriosa de imitar a Francisco Javier y ganar el premio de la salvación. ${ }^{19}$ Pero, sobre todo, fue consecuencia de la necesidad de organizar y dar sentido a esa nueva realidad colonial hasta que los jesuitas fueron expulsados de las posesiones de ultramar (1768). ${ }^{20}$

\section{LOS PRIMEROS CONTACTOS}

La historia de las Marianas se caracteriza por un primer período marcado por la conquista y asentamiento de los españoles en las Filipinas (1521-1668).21 Desde el supuesto desembarco de Fernando de Magallanes en las islas Maria-

${ }^{16}$ A diferencia de las «fronteras coloniales», que proyectan una dimensión eurocéntrica, el término «contact zone» is an attempt to invoke the spatial and temporal copresence of subjects previously separated by geographic and historical disjunctures, and whose trajectories now intersect» (Marie Louis PRATT, Imperial Eyes. Travel Writing and Transculturation, London \& New York: Routledge, [1992] 1997, 6-7).

17 Christophe GiUdicelli, «Pacificación y construcción discursiva de la frontera. El poder instituyente de la guerra en los confines del Imperio (siglos XVI-XVII)», en: Bernard LAVALLÉ (eds.), Máscaras, tretas y rodeos del discurso colonial en los Andes. Lima, IIFEA \& PUCP, 2005, 157-173.

18 Según Vicente MuÑoz BARREDA, los jefes marianos tenían la costumbre de raparse la cabeza, la barba y las cejas, por lo cual los españoles los llamaron chamorros, que en portugués significa «rapados» (La Micronesia española o los archipiélagos de Marianas, Palaos y Carolinas. Manila: Tipografía «Amigos del País», 1894, 44-45).

${ }^{19}$ Existía la idea comúnmente aceptada de que el martirio confería automáticamente la santidad a la víctima, pero comprometía seriamente los proyectos misionales que la Compañía se había propuesto (Kenneth L. WoOdWARD, La fabricación de los santos. Barcelona: Ediciones B [1990] 1991, 52; Javier BurrieZA SÁNCHEZ, Jesuitas en Indias: entre la utopía y el conflicto. Trabajos y misiones de la Compañía de Jesús en la América moderna. Valladolid: Universidad de Valladolid, 2007, 59).

${ }^{20}$ Algunas hagiografías de Francisco Javier ilustran esa necesidad de «organizar y dar sentido» a las posesiones portuguesas en Asia. Al respecto, véase Ines G. Županov, «The Prophetic and the Miraculous in Portuguese Asia: a Hagiographical View of Colonial Culture», en Sanjay SUBRAHMANYAM (eds.), Sinners and Saints. The Successors of Vasco da Gama, New Delhi: Oxford UP, 1995, $135-161$.

21 James B. Tueller, «Los chamorros de Guam y la colonización española: una tercera etapa, 1698 a 1747», en: Mª Dolores Elizalde PÉrez-Grueso, Josep Ma Fradera \& Luis Alonso (ed.), Imperios y naciones en el Pacífico. Volumen II. Colonialismo e identidad nacional en Filipinas y Micronesia. Madrid: CSIC, 2001, 385. 
nas, como las bautizó el navegante portugués en 1521, sus habitantes habían permanecido en el más absoluto ostracismo. ${ }^{22} \mathrm{El}$ archipiélago (también conocido como de las Velas Latinas o de los Ladrones) tenía unas trece islas, volcánicas y coralíferas, algunas de las cuales eran pequeñas y casi deshabitadas (terrae nullius), que se extendían formando una larga cadena en dirección norte hacia el Japón en unas 500 millas hacia la pequeña isla de Farallón de Medinilla.23

$\mathrm{Su}$ clima era tropical, con pantanos, ríos caudalosos y muchos árboles. ${ }^{24}$ Los nativos vivían en casas construidas en madera de coco y techadas con hojas de higuera. Estaban acostumbrados a comerciar con los habitantes de las islas vecinas utilizando sus famosas proas o parotos, por lo que no es extraño que se aproximaran a las naves españolas con agua y comida. Según la Relación (1524) del italiano Antonio Pigafetta, los españoles aceptaron los víveres sin ofrecerles nada a cambio, lo que provocó que abordaran sigilosamente sus naves llevándose diversos objetos e incluso «el esquife amarrado a la popa de la nave capitana (Trinidad)». Colérico, Magallanes desembarcó en la isla con cuarenta ballesteros y se enfrentó a los aguerridos nativos, incendiando sus poblados y matando a siete de ellos. ${ }^{25}$ Este «desencuentro» marcó las futuras relaciones entre colonizadores y colonizados. ${ }^{26}$

A partir de entonces, diversas expediciones españolas visitaron la isla de Guam, Guahan o Guguán (desde España, la expedición de Juan García Jofre de Loaysa y Juan Sebastián del Cano, 14/9/1526; la de Álvaro de Saavedra Cerón, 29/12/1527; desde la Nueva España, la de Miguel López de Legazpi-Andrés de Urdaneta, 22/1/1565) con el fin de avituallarse de agua y frutos frescos de la tierra (principalmente cocos, plátanos, higos y caña de azúcar) hasta que la Corona tomó formalmente posesión de la isla el 22 de enero de $1565 .{ }^{27} \mathrm{Se}$

\footnotetext{
22 Todavía hoy, el desembarco de Magallanes en las Marianas continúa siendo un misterio. Al respecto, véase Robert F. ROGERS \& Dirk Anthony BALLENDORF, «Magellan's Landfall in the Mariana Islands». The Journal of Pacific History, 24:2, 1989, 193-208.

${ }^{23}$ Las Marianas se componen de las islas de Guam (San Juan), Rota o Zarpana (Santa Ana), Aquigán (Santo Ángel), Tinian (Buena Vista Mariana), Saipán (San José), Anatahán (San Joaquín), Guguán (San Felipe), Sariguán (Sar Carlos), Alamagán (La Concepción), Pagán (San Ignacio), Agrigán (San Francisco Javier), Asonsón (Asunción), Maug (San Lorenzo). El grupo de islas llamado «Gani» se situaba al norte y estaba compuesto de ocho pequeñas islas, entre las cuales destacan las citadas Anatahán, Maug, Asonsón, Agrigán y Alamagán (Felipe de la Corte y Ruano Calderón, Memoria descriptiva e histórica de las islas Marianas. Madrid, Imprenta Nacional, 1875, 12; Francis X. Hezel, SJ, From conquest to Colonization. Spain in the Marian Islands, 1690 to 1740. Saipan: Division of Historic Preservation, 1989, 10-13).

${ }^{24}$ Mario D. Zamora, Los indígenas de las islas Filipinas. Madrid, Maphre, 1992, 281-282.

25 Antonio Pigafetta, Primer viaje alrededor del mundo, Edición de Leoncio Cabrero Fernández. Madrid: Dastin [1524] 2002, 72-75.

26 ZAMORA, Los indígenas de las islas Filipinas, 283-284.

${ }^{27}$ Antonio Molina, América en Filipinas. Madrid, Fundación Maphre, 1992, 28; Amancio Landín CARrasco, «Descubrimientos españoles en la Micronesia», en: Javier Galván GuiJo, (comisario), Is-
} 
trataba de una parada obligada para el Galeón de Manila que desde 1602 conectaba Manila con Acapulco en lo que vino a ser el auténtico «cordón umbilical» de las relaciones políticas y comerciales entre el archipiélago filipino y Nueva España. ${ }^{28}$ Las características de la economía-mundo, basada en un sistema comercial transoceánico, exigían el control de los territorios estratégicos y su administración. ${ }^{29}$

Sin embargo, a pesar de que el virrey de Nueva España, don Martín Enríquez de Almansa (1568-1580), concedió el título de adelantado de las islas de los Ladrones a López de Legazpi (1568), los contactos con los nativos fueron prácticamente inexistentes. La nao capitana «San Pedro» estuvo muy poco tiempo anclada y su estancia se limitó a reclamar aquel archipiélago en nombre de la Corona española.

Las primeras estampas de los chamorros corresponden a la Relación de Pigafetta: eran gente pobre, ingeniosa y ladrona, ${ }^{30} \sin$ «concierto ni policía», que no atendían a ninguna autoridad divina o humana. De cabellos negros y tez olivácea, eran bien proporcionados y andaban todos prácticamente desnudos. Las mujeres, de piel más blanca que los hombres, llevaban los cabellos muy largos y sueltos y se pintaban los dientes de color rojo y negro, cubriéndose el sexo con una especie de hoja de palmera, o tifis. Los únicos ornamentos que portaban eran sombreros de palma, pero ni rastro de oro, perlas u otras riquezas que pudieran interesar a los hombres de Magallanes. Tampoco llevaban armas, ex-

las del Pacífico: el legado español. Madrid, Ministerio de Educación y Cultura, 1998, 17-25; Omaria BRUNAL-PERRY, «Las islas Marianas enclave estratégico en el comercio entre México y Filipinas», en: Leoncio CABrero (eds.), España y el Pacífico. Legazpi. Tomo I, Madrid, Sociedad Estatal de Conmemoraciones Culturales, 2004, 543-46.

28 Antonio Molina, Historia de Filipinas. Madrid, Ediciones Cultura Hispánica del Instituto de Cooperación Iberoamericana, 1984, 72; 103-104; MolinA, América en Filipinas, 99-108; Carmen YUSTE LÓPEZ, «El galeón traspacífico. Redes mercantiles alrededor de especias, textiles y plata», en Miguel LuQue Talaván \& Marta M. Manchado López (coord.), Un océano de intercambios: Hispanoasia (1521-1898). Un homenaje al profesor Leoncio Cabrero Fernández, Tomo I, Madrid: AECI, 2008, 195-216.

${ }^{29}$ Pedro Pérez Herrero, «Nueva España, Filipinas y el galeón de Manila (siglo XVI-XVIII)», en: $\mathrm{M}^{\mathrm{a}}$ Dolores Elizalde PéReZ-Grueso (eds.), Las relaciones entre España y Filipinas. Siglos XVI-XX. Madrid-Barcelona: CSIC \& Casa Asia, 2002, 52; Antonio-Miguel BERNAL, «La «Carrera del Pacífico»: Filipinas en el sistema colonial de la Carrera de Indias», en: Leoncio CABRERo (eds.), España y el Pacífico. Legazpi. Tomo I. Madrid: Sociedad Estatal de Conmemoraciones Culturales, 2004, 493.

${ }^{30}$ El 8 de mayo de 1683, el jesuita Manuel de Solórzano (1649-1684) cuestionó esta común opinión, escribiendo que «aunque tienen nombre de ladrones, el hurto es tan poco usado entre ellos que todas las casas están abiertas» (Manuel de SolóRZANO, «Descripción de las islas Marianas, costumbres de sus naturales. Una relación del estado en que se hallaban las misiones que había en ellas con el número de convertidos a Nuestra Santa Fe; varios acatamientos y persecuciones padecidas por los padres dimanado de una falsa semilla aparecida por cierto sangley y choco; y algunos casos maravillosos que Dios obro a favor de su causa y para confusión de la idolatría» (1683) (Biblioteca del Palacio Real, II/2866, ff. 126r-127r). 
cepto una especie de jabalinas con la punta de hueso, afilada, que resultaban de lo más inquietantes. ${ }^{31}$

Otras expediciones, como la segunda expedición del adelantado coruñés Álvaro de Mendaña y Neira (Lima, 1595-96),32 a la que siguió la del que fuera su piloto mayor, el portugués don Pedro Fernández de Quirós y su lugarteniente, el también portugués Luis Váez de Torres (Lima, 1605-1606), ${ }^{33}$ se acercaron a las islas, pero con escasas repercusiones entre españoles y chamorros. Hubo que esperar al naufragio del franciscano fray Juan Pobre de Zamora para tener la primera Relación (1598-1603) de un religioso entre los chamorros. ${ }^{34}$

\section{DE LOS LADRONES A LAS MARIANAS}

Desde los momentos iniciales de la colonización, el interés económico de la Corona española sobre las islas Marianas fue escaso. Las expediciones novohispanas se dirigían al archipiélago filipino buscando dominar el mercado europeo de las especias. Este modelo colonial fue pronto sustituido por otro basado en la carrera comercial Acapulco-Manila. Tras la publicación del Reglamento de Galeones, que atribuyó el monopolio comercial a los hispano-mexicanos (1593), el archipiélago mariano ganó interés por su situación estratégica como centro de avituallamiento de las embarcaciones que se dirigían a uno u otro lado del Pacífico. ${ }^{35}$

La reformulación del proyecto filipino en los años ochenta, transformó las Filipinas en un espacio de intercambio comercial entre China y Nueva España. ${ }^{36}$

31 PigafetTa, Primer viaje alrededor del mundo, 73-74. Véase también Laura THOMPSON, «The Native Culture of the Marianas Islands» Benice P. Bishop Museum. Bulletin 185, Honolulu, Hawaii \& New York, Kraus Reprint Co. [1945] 1971, 10-11.

32 Citado en Pedro Fernández DE Quirós, Descubrimiento de las regiones australes. Edición de Roberto Fernando Pérez. Madrid: Dastin, 2000, 151-52. Véase también ThOMPSON, «The Native Culture...», 31-33.

${ }^{33}$ QUIRÓs, Descubrimiento de las regiones australes, 285.

34 Fray Juan PoBre llegó a las islas a bordo de un patache rezagado que acompañaba al galeón «Santo Tomás». Permaneció casi un año en la isla de Guam hasta que fue recogido por el galleon «Jesús María» (Antonio DE MorgA, Sucesos de las islas Filipinas. Edición crítica y comentada de Francisca Perujo. México: FCE, [1609] 2007, 150-152; 165-166; Marjorie G. DrIVER, «Notes and Documents. Fray Juan Pobre de Zamora and his Account of the Mariana Islands». Journal of Pacific History, 18:3 (1983) 198-216).

35 Omaira Brunal-Perry, «Los misioneros españoles en las Marianas», en: Javier Galván Guijo (comisario), Islas del Pacífico: el legado español, Madrid, Ministerio de Educación y Cultura, 1998, 97; Brunal-Perry, «Las islas Marianas enclave estratégico...», 543-555.

${ }^{36}$ Luis Alonso ÁlvareZ, «Formación y desarrollo del proyecto colonial español en las islas Filipinas, 1565-1762», en: Gloria CANo \& Ana Delgado (eds.), De Tartesos a Manila. Siete estudios coloniales y poscoloniales, València: PUV, 2008, 153-170.

Hispania Sacra, LXIII

128, julio-diciembre 2011, 707-745, ISSN: 0018-215-X 
A mediados del siglo XVII, los holandeses se lanzaron a las Indias orientales esperando competir por los productos chinos y americanos (sedas, cera, loza, damascos, plata). Para proteger el flanco occidental del imperio americano era preciso que los costes de mantenimiento de las islas no fuesen demasiado onerosos para las arcas reales. El procurador general de Manila, don Juan Gran y Monfalcón, escribió un Memorial al Rey (1637) insistiendo en la necesidad de asegurar la presencia española en las islas ${ }^{37}$ Como el clero regular constituía la población más estable, los españoles recurrieron a los frailes agustinos, franciscanos y dominicos por su capacidad para movilizar a sus parroquianos nati$\operatorname{vos} .^{38}$

Sin embargo, la Corona encargó la «conquista espiritual» de las Marianas a la Compañía de Jesús. Varias son las razones que explican esta decisión. Por un lado, las autoridades gubernamentales contemplaban a los jesuitas como una «religión de apóstoles» comprometidos en la predicación del evangelio. ${ }^{39}$ Pero no todos actuaban de la misma forma. En una carta que escribió al Consejo de Indias, con fecha 9 de mayo de 1651, el gobernador don Diego Fajardo (16441653) lamentaba el proceder de los dominicos y franciscanos de Propaganda Fide quienes tan pronto arribaban a las Filipinas no deseaban otra cosa que pasar a los reinos del Japón y China. Por el contrario, elogiaba a la Compañía de Jesús en la isla de Mindanao, donde los jesuitas, encabezados por su provincial, el padre Juan de Salazar, tenían «al presente casi la mayor parte de la isla del Reino de Midanao y de otros a él circunvecinos reducidas a la fe; lo que de las armas V. M. no han podido conseguir».40

Por el otro, el poder del águila bicéfala descansaba sobre los hombros de la reina Mariana, archiduquesa de Austria (1634-1696) y de su maestro espiritual y confesor, el jesuita austríaco Juan Everardo Nithard (1607-6081), quien utilizó su influencia para apoyar a sus hermanos de religión. La debilidad política y econó-

37 ÁLVAREZ, «Formación y desarrollo...», 153-154.

38 Antonio García Abasolo, «Formación de las Indias orientales españolas. Filipinas en el siglo XVI», en: Leoncio CABRERO (coordinador), Historia General de Filipinas. Madrid: Ediciones de Cultura Hispánica, 2000, 169-205; Antonio GARCía ABASOLO, «La primera exploración del Pacífico y el asentamiento español en Filipinas», en: $\mathrm{M}^{\mathrm{a}}$ Dolores ElizALDE PÉREZ-GruESo (eds.), Las relaciones entre España y Filipinas, 21-35.

39 John Leddy O'Phelan, The Hispanization of the Philippines. Spanish Aims and Filipino Responses, 1565-1700. Madison, Milwaukee \& London: Wisconsin UP, [1959] 1967, 37-38.

40 Pablo Pastells, SJ, Catálogo de los documentos relativos a las islas Filipinas existentes en el Archivo General de Indias (AGI). Tomo IX. Barcelona: Compañía General de Tabacos de Filipinas, Tomo IX, 1934, CV. La cursiva es mía. John L. O'PHelan (The Hispanization..., 43-44) y Jaume GoRRIZ Abella («La Compañía de Jesús», en: Leoncio CABrero (eds.), España y el Pacífico. Legazpi. Tomo II. Madrid: Sociedad Estatal de Conmemoraciones Culturales, 2004, 362) también señalan que para muchos misioneros regulares, particularmente los frailes descalzos, las misiones filipinas no eran sino un mero puente para la penetración en China y Japón. 
mica del imperio español después de la firma del tratado de paz entre Madrid y las Provincias Unidas en Münster, Westfalia (1648), unida a las conexiones del padre Nithard y a su posición clave en la corte española, favoreció los proyectos misionales de la Compañía de Jesús en Filipinas, situándolos en la órbita de los Habsburgo.

Las islas Marianas (1668) se situaban en una posición estratégica para el control del comercio transoceánico en el Pacífico occidental. A causa de las peligrosas corrientes, los galeones evitaban fondear en la isla de Guam, o San Juan, lo que de ningún modo significaba que los piratas holandeses no pudieran apoderarse de ella y hostigar desde allí la ruta del Galeón ManilaAcapulco.

La idea de que aquellas colonias podrían sostenerse con unos pocos soldados y misioneros fue compartida por Diego Luis de San Vítores y auspiciada por la Corona..$^{41}$ Ciertamente, como pensaba Campanella (1568-1639), «las armas nada pueden contra una religión si se resisten con otra religión más fuerte, aunque sea peor, si el pueblo la acepta». ${ }^{42}$ No hay duda de que el padre San Vítores consideraba a Dios como la causa primera del Imperio cristiano. Y también que una gran ocasión se presentaba para los jesuitas en las Filipinas, donde había infinidad de islas cuyos habitantes no habían oído nunca la palabra de Dios. Con el propósito de apacentar aquellas ovejas se embarcó el 5 de abril de 1662 en Acapulco en el galeón «San Damián» con dirección a Manila. A los tres meses llegaba a la isla de Guam, comprobando que efectivamente, las poblaciones de las islas y de las llamadas Marianas del Norte -Saipán, Tinian y Rota- carecían de atención religiosa. ${ }^{43}$

Los españoles integraron a sus habitantes dentro de la categoría de pueblos «salvajes» o «infieles». El 10 de julio San Vítores arribó al puerto de Lampón, en Manila, encontrándose con una población bajo los efectos de revueltas interiores y amenazas exteriores. ${ }^{44}$ Por entonces el pirata chino Chen Che'en Kung, más conocido como «Coseng» $\mathrm{o}$ «Koxinga», contaba con un poderoso ejército en la zona de Fukien, en China continental, desde donde disputaba a los holandeses el monopolio comercial de la antigua misión dominica de Formosa (que

\footnotetext{
${ }^{41}$ O'Phelan, The Hispanization, 8-9; 56.

42 Tomasso Campanella, La Monarquía Hispánica (Madrid: Centro de Estudios Constitucionales, 1991), 32 .

${ }^{43}$ Horacio DE LA CosTa, SJ, The Jesuits in the Philippines: 1581-1768. Cambridge, Massachusetts: Harvard UP, 1961 , 455. Como señala PÉREZ HERRERO, las naves partían de Acapulco a finales de febrero, y si no surgía ningún contratiempo, llegaban a Manila doce semanas después («Nueva España, Filipinas y el galeón de Manila...», 52).

${ }^{44}$ PASTElls, Catálogo de los documentos relativos a las islas Filipinas, Tomo IX, 1934, CXLIICLII; Ana M ${ }^{a}$ PRIETo LuCENA, Filipinas durante el gobierno de Manrique de Lara (1653-1663). Sevi1la: CSIC, 1984, 53-83.
} 
los españoles perdieron en 1642), Taiwán y Japón. Pero lo que preocupaba a las autoridades políticas de las Filipinas era su amenaza de incorporar el archipiélago filipino a sus dominios. ${ }^{45}$

Mientras tanto, el padre San Vítores trabajaba como misionero en las provincias de Tagalos, Mindoro y Cavite, donde le enseñó el tagalo el hermano asistente Marcos Cruz. ${ }^{46}$ Fue maestro de novicios en Manila y prefecto de estudios en la Universidad, desde donde promovió las misiones populares y el acto de contrición. ${ }^{47}$ Lamentaba que, ante la presencia del peligro, algunos de sus cofrades abandonaran a los neófitos, quienes se convertían en apóstatas de la fe. Para evitarlo, en 1663 escribió a Juan Pablo Oliva, Prepósito General de la Compañía (1664-81), sobre la necesidad de fundar una viceprovincia en las Marianas, pues sus habitantes nunca habían visto a un clérigo. Uno de los principales impedimentos era la falta de recursos humanos, pero también el hecho de que tuvieran que ocuparse de las doctrinas que los jesuitas tenían en Taytay y Cainta. ${ }^{8}$ En lugar de convertirse en «párrocos de indios», San Vítores pensaba que los jesuitas debían ocuparse de las misiones itinerantes, siguiendo el espíritu apostólico de Francisco Javier, formando grupos de vanguardia capaces de defender y propagar el evangelio en las Filipinas. ${ }^{49}$

En 1664, regresó a Manila el almirante Esteban Ramos junto con cuatro filipinos que habían permanecido durante veintiséis años en las Marianas, víctimas del naufragio del galeón «Nuestra Señora de la Concepción» frente a la isla de Saipán (1638)..$^{50}$ Los náufragos saltaron de isla en isla hasta que algunos consiguieron regresar a las Filipinas.$^{51}$ Durante su «exilio» en la isla

45 Prieto LuCEnA, Filipinas durante el gobierno de Manrique de Lara, 116-128; Lourdes DíAZTrechuelo, Filipinas. La gran desconocida (1565-1898). Pamplona: Universidad de Navarra, 2001, 148-52.

${ }^{46}$ Francisco García, SJ, Vida y Martirio del Venerable padre Diego Luis de Sanvitores de la Compañía de Jesús. Madrid: Imprenta de Juan García Infanzón, 1683, ff. 116-17; AsTrAIN, Historia, Tomo VI, 805 .

47 Como apunta Broggio, «Sanvítores ne se limita pas a transplanter en Extrême-Orient des cérémonies déjà en usage dans la mère patrie: il conçut des techniques nouvelles qui tiraient profit de l'expérience acquise dans les missions intérieures» (Paolo BROGGIO, «L'acto de contrición entre Europe et Nouveaux Mondes. Diego Luis de Sanvítores et la circulation des stratégies d'évangélisation de la Compagnie de Jesús au XVIIe siècle», en: Pierre-Antoine FABRE \& Bernard VINCENT (eds.), Missions religieuses modernes. «Notre lieu est le monde». Roma: École Française de Rome, 2007, 251).

48 O'Phelan, The Hispanization, 41.

49 Sobre la influencia de Francisco Javier en la idea jesuita de misión, véase Buenaventura DE CARROCERA, OFM, «Ideas misionológicas de San Francisco Javier», Missionalia Hispánica, Año IX, 27 (1952) 644-654; BurRIEZA SÁNCHEZ, Jesuitas en Indias, 79-80.

50 Florentino RodAo, «España en el Pacífico», en: Javier Galván Guijo (comisario), Islas del Pacífico: el legado español. Madrid: Ministerio de Educación y Cultura, 1998, 28.

${ }^{51} \mathrm{Al}$ respecto, véase la carta que escribió el padre Ezquerra, con fecha en Agaña, 3 de mayo de 1672 (Bibliotheca Americana et Philippina, Part. III. Catálogo nº 442. Maggs Bross, 104-105). 
de Guam o San Juan, habían aprendido la lengua chamorra y se convirtieron en intérpretes. En un informe de 1665 confirmaba que los isleños eran «gente dócil y afable, y que no tienen secta, ni ritos, ni otros vecinos que se las enseñen», concluyendo que la evangelización era empresa «de muy poca costa, pues basta, que con los religiosos vayan cantidad de veinte españoles, y otros tanto naturales de estas islas (...) por ser aquella gente muy pacífica, y sin borracheras». 52

Resuelto a aquella conquista espiritual, el futuro «apóstol de los chamorros» escribió un Memorial dirigido a su padre don Jerónimo de San Vítores, del Consejo de Hacienda, con fecha 29 de mayo de 1665, en el que argumentaba las razones para fundar la misión. Se trataba de un grupo de islas pequeñas donde los gentiles que las habitaban no habían escuchado nunca la palabra de Dios. La posibilidad de que ningún pecado original los hubiera corrompido se extendía como un leit motiv para organizar una expedición. A diferencia de los nativos de las Visayas o de otras islas de las Filipinas, los indios chamorros no habían tenido contacto con los musulmanes, lo que jugaba a su favor. Sin embargo, al jesuita le preocupaba la gran distancia que les separaba de Manila, especialmente por la falta de misioneros en la provincia. ${ }^{53}$

A pesar de las dificultades, los superiores aceptaron el proyecto. A continuación se entrevistó con el arzobispo criollo Miguel Millán de Poblete (16531667) para poder organizar una misión religiosa a las islas. ${ }^{54} \mathrm{Su}$ principal valedor en la corte fue su propio padre, don Jerónimo de San Vítores, quien presentó el citado Memorial al presidente del Consejo de Indias, don Alonso Fernández de Lorca. Los argumentos eran casi los mismos presentados a las autoridades políticas de Manila. La causa principal para la conquista y conservación de las islas Filipinas había sido la de «alumbrar las gentes que habitan estas regiones en las tinieblas de su ceguedad y cautiverio del demonio». La Corona española tenía, pues, la obligación moral de acudir al rescate de tantos indios desamparados que vivían sin doctrina, so pena atraer para sí los castigos divinos. Pero las dificultades económicas de la hacienda real no permitían acometer semejante empresa.

El gobernador de las Filipinas, don Diego de Salcedo (1663-68) no pudo -o no quiso- hacerse cargo de la misión. A diferencia de los Virreinatos del Perú y Nueva España, los vecinos de Manila eran un grupo social minoritario escasamente interesado en llevar a cabo costosas campañas de conquista a la lejana

\footnotetext{
${ }^{52}$ AGI, Filipinas 82, ff. 1r-2v.

${ }^{53}$ AGI, Filipinas 82, citado en Astrain, Historia, Tomo VI, 808-809.

${ }^{54}$ Para más información sobre el arzobispo Poblete, véase DE LA CosTA, The Jesuits, 426-429; MoLINA, América en Filipinas, 61.
} 
Micronesia (Marianas, Carolinas y Palaos), que consideraban de escaso valor. Eran pocos y se dedicaban principalmente al comercio de productos orientales entre Filipinas y Acapulco. .55

Como la Corona debía reducir los gastos de mantenimiento de una fuerza militar en las fronteras del Imperio, la llegada de los misioneros jesuitas supuso una forma de contener el avance de los musulmanes y del resto de potencias coloniales que se extendían por los mercados asiáticos. Definitivamente, el Pacífico había dejado de ser el «lago español» para convertirse en un espacio de frontera del imperio hispánico. Entre 1645 y 1646 los holandeses prepararon cuatro flotas con las que pretendían expulsar a los españoles del Oriente. ${ }^{56}$ Para proteger las rutas comerciales con Manila los españoles lanzaron al mar dos auténticos acorazados (los galeones «Nuestra Señora de la Encarnación» y «Nuestra Señora del Rosario») con los que consiguieron vencer a los «herejes holandeses» en la batalla de Playa Honda (abril, 1646). ${ }^{57}$ Sin embargo, los holandeses no cejaron en su empeño y en junio de 1647 regresaron con una nueva flota de doce buques al mando del almirante Martin Gertzen. Penetraron hasta la bahía de Manila, atacando el puerto de Cavite (donde se fabricaban los galeones) y saqueando los pueblos costeros de Bataán, Abucay y Sámal, en la provincia de la Pampanga. ${ }^{58}$ De nuevo, marinos españoles y filipinos consiguieron expulsarlos hacia sus posesiones en Batavia (Indonesia), donde llegaron maltrechos y con muchas bajas. ${ }^{59}$

Tras la firma del Tratado de Westfalia (1648), España reconoció la independencia de Holanda. Sin embargo, las continuas guerras habían dejado un panorama desolador. A principios de 1650 las defensas eran precarias o estaban desatendidas, correspondiendo a los frailes la tarea de movilizar a los habitantes de las islas para defenderse de los continuos ataques de los piratas. Las exploraciones y conquistas de los almirantes holandeses habían arruinado el comercio. Esto, unido a los terremotos, tifones y naufragios, como el del 30 de noviembre de 1645 , desolaciones y revueltas internas, convertía las islas en un lugar poco atrayente. ${ }^{60}$ Hasta la firma del Tratado de los Pirineos (1659), la Corona española mantenía diversos frentes de guerra a la vez. Defender las colonias era cada vez más oneroso para la hacienda real. Faltaban soldados y

\footnotetext{
${ }^{55}$ GARCía ABASOLO, «La primera exploración del Pacífico...», 28.

${ }^{56}$ En 1645 llegó a las Filipinas una expedición holanda que fue derrotada por las fuerzas locales (PASTElls, Catálogo de los documentos relativos a las islas Filipinas, Tomo IX, LXIII).

${ }^{57}$ GuTIÉRreZ, Historia de la iglesia en Filipinas, 186.

58 Pastells, Catálogo de los documentos relativos a las islas Filipinas, Tomo IX, LXXIX-LXXX. Véase Díaz-Trechuelo, Filipinas. La gran desconocida, 148.

${ }^{59}$ GutiérReZ, Historia de la iglesia en Filipinas, 187.

60 PASTElls, Catálogo de los documentos relativos a las islas Filipinas, Tomo IX, XCVIII; GARCíA-ABASOLO, «Formación de las Indias orientales españolas...», 202.
} 
suministros. Gobernadores como don Sebastián Hurtado de Corcuera (163544) y don Diego Fajardo (1644-53) solicitaron periódicamente que se enviaran recursos materiales y humanos a las Filipinas (y luego a las Marianas), lo que no siempre sucedió con puntualidad. ${ }^{61}$ Para salvaguardar la hegemonía española en las «islas del Poniente», primero había que someter a los indios rebeldes a la Corona. Y para ello era indispensable garantizar la seguridad de las órdenes religiosas en las islas. ${ }^{62}$ Dicho de otro modo, el papel que los frailes jugaron en el mantenimiento de las islas no puede desligarse del deber de la Corona de establecer la Iglesia y ayudarla en su obra evangelizadora - Patronato Regio. ${ }^{63}$

\section{MARTIRIO Y SANTIDAD}

La muerte de Felipe IV (1621-65) dejó la monarquía hispánica en una grave crisis ${ }^{64} \mathrm{Su}$ viuda, la reina Mariana, hija del emperador Fernando III y desposada en segundas nupcias con el rey en 1649, no estaba interesada en asuntos de gobierno. Correspondió al jesuita austríaco Juan Everardo Nithard, confesor y director espiritual de la reina, el papel de consejero valido de la corte. ${ }^{65}$ Las relaciones con la monarquía habían sido siempre excelentes. El día 4 de junio de 1665, la reina gobernadora Mariana envió una Real Cédula apoyando el proyecto de San Vítores y bendiciendo su misión, asignando 21.000 pesos para la subvención y defensa de las islas. Un gesto que pretendía devolver al imperio la protección divina que parecía haber perdido. Los jesuitas, agradecidos, cambiaron el nombre de los Ladrones por el de las Marianas, en honor de la Virgen María y de la reina gobernadora. ${ }^{66}$

${ }^{61}$ Muchos de los soldados que llegaron eran niños mestizos e indios de 10, 12 o 14 años de edad, con escasa preparación militar, que no podían emplearse en las guerras hispano-holandesas o hispanomahometanas. Se llegó, incluso, a contratar holandeses convertidos al catolicismo como mercenarios (Ostwald SALEs Colín, «La escasez de soldados en las Filipinas de la primera mitad del siglo XVII», en: Antonio Gutiérrez Escudero \& María Luisa Laviana Cuetos (coord.), Estudios sobre América. Siglos XVI-XX. La Asociación España de Americanistas en su Vigésimo Aniversario. Sevilla: AEA, 2005, 786-788).

62 Por medio de la Real Cédula del 6 de junio de 1671, la Corona solicitó información sobre la necesidad de enviar soldados y armas para proteger a los misioneros de las Marianas, lo que se confirmó con posterioridad (Archivo General de la Nación de México (en adelante, AGN). Índice Ramo Cédulas Reales. Vol. 12. Exp. 53, ff. 151-52). Nuevamente, el 12 de agosto de 1671, se expidió una nueva Real Cédula por la que se solicitaba la misma información (AGN, Índice Ramo Cédulas Reales. Vol. 12. Exp. 89, ff. 229-230).

${ }^{63}$ García Abasolo, «Formación de las Indias orientales españolas...», 196-197; GARCÍA ABASOLO, «La primera exploración del Pacífico...», 28.

64 John H. Eliot, España, Europa y el mundo de ultramar, Madrid: Taurus, 2009, 74.

65 Julián J. Lozano Navarro, La Compañía de Jesús y el poder en la España de los Austrias. Madrid: Cátedra, 2005, 297-324; Javier BuRRIEZA SÁNCHEZ, «Las Glorias del segundo siglo (16221700)», en: Teófanes EGIDo (eds.), Los jesuitas en España, 169-171.

66 Astrain, Historia, Tomo VI, 811; DE LA Costa, The Jesuits, 456.

Hispania Sacra, LXIII

128, julio-diciembre 2011, 707-745, ISSN: 0018-215-X 
La solución para financiar los gastos de la conquista y conversión de las Marianas pasaba por ir a la Nueva España y solicitar el apoyo económico del Virrey. Así, el 7 de agosto de 1667, San Vítores salió del puerto de Cavite en el galeón «San Diego» con dirección a México, acompañado del padre palentino Tomás Cardeñoso ${ }^{67}$ y del hermano donado Felipe Sonsón, ${ }^{68}$ con el fin de obtener los fondos necesarios para subvencionar la misión de Guam. Llegó el 14 de enero de 1668 y se entrevistó con el Virrey de Nueva España, Marqués de Mancera, quien le proporcionó 10.000 pesos de las Cajas Reales, así como diversos sirvientes y otros donativos. Los caballeros de la congregación de San Francisco Javier, dirigidos por Cristóbal Javier Vidal, hermano del jesuita José Vidal, a la sazón procurador de las Marianas, actuaron como avaladores del jesuita. ${ }^{69} \mathrm{Su}$ persistencia hizo que en abril partiera de vuelta a Guam en una alegoría de la «Nave de la Iglesia Militante» con cinco jesuitas: los padres Tomás Cardeñoso, el malagueño Luis de Medina, ${ }^{70} \mathrm{el} \mathrm{al-}$ meriense Pedro de Casanova (1641-1694), ${ }^{71}$ el vallisoletano Luis Martín de Morales (1641-1716), ${ }^{72}$ y el hermano escolar teólogo burgalés Lorenzo Bustillos (1642-1716), quienes salieron de Acapulco el 23 de marzo de 1668 y llegaron a las Marianas el sábado 16 de junio del mismo año. ${ }^{73}$

\footnotetext{
${ }^{67}$ El hermano Cardeñoso nació en Paredes en 1640. Entró en la Compañía en 1664. Era operario de indios (ARSI, «Primus Catalogus Anni Personarum Anni 1672». Philippinae Cat. Trien. 1649-1696, Tomo 2-II, f. 381v).

${ }^{68}$ Los donados eran aquellos que sin haber hecho los votos de una orden religiosa, servían como ayudantes y auxiliares a los sacerdotes, permaneciendo como laicos en el sentido estricto del término (John N. Schumacher, SJ, «Early Filipino Jesuits: 1593-1930», Philippine Studies, 29 (1981) 273). Sobre el hermano donado - con hábito pero sin profesión ni noviciado- Felipe Sonsón, véase ScHUMACHER, «Felipe Sonsón...», 266-285.

${ }^{69} \mathrm{El}$ Archivum Historicum Societatis Iesu (ARSI), en Roma, conserva el Memorial que el padre San Vítores dirigió a los caballeros de la Congregación de Francisco Javier de México, describiendo las islas así como las relaciones de los primeros viajes de los adelantados Álvaro de Mendaña (1595) y Pedro Fernández de Quirós (1610). Finalmente, San Vítores argumentaba acerca de los motivos para no dilatar más la reducción y doctrina de las islas de los Ladrones y los medios para llevar a cabo la misión (ARSI, Fondo Gesuítico, 849).

${ }^{70}$ Para una pequeña biografía del padre Medina, véase la carta martirial del padre Luis de Medina (Arxiu Históric de la Companyia de Jesús a Catalunya (en adelante, AHCJC), Carpeta «EI.b-9/5/4. «Mártires de la Provincia de Filipinas de la Compañía de Jesús. Manila, 12 de mayo de 1903», contenida en la carpeta EI/b-9/5/1-7. Dichos documentos se encuentran en un clasificador, bajo el título de «Martirios y varones ilustres».

${ }^{71}$ El padre Pedro Casanova nació en Almería el 26 de agosto de 1641. Entró en la Compañía en 1658 y en 1672 había hecho los votos de escolar (ARSI, «Primus Catalogus Anni Personarum Anni 1672». Philippinae Cat. Trien. 1649-1696, Tomo 2-II, f. 363r).

${ }^{72}$ El padre Luis Martín de Morales nació en Valladolid en 1644. Entró en la Compañía de Jesús en 1657. En 1671 había hecho los votos de escolar (ARSI, «Primus Catalogus Anni Personarum Anni 1671». Philippinae Cat. Trien. 1649-1696, Tomo 2-II, f. 353v).

73 «Resumen de los sucesos del primer año de la misión en estas islas Marianas», con fecha en San Ignacio de Agaña, 26 de abril de 1666 (ARSI, Philippine Historiae, 1663-1734, Tomo 13, ff. 5r-8v). El hermano Bustillos continuó su viaje hasta Manila, no volviendo a las Marianas hasta 1675 (MURILLO Velarde, Historia, f. 336; DE la Costa, The Jesuits, 456).
} 
Desembarcaron en una playa del norte de Guam y plantaron una cruz como símbolo de Cristo frente al diablo. Los jesuitas habían llegado con el fin de expulsarlo de las Marianas y para ello tomaron posesión del archipiélago en una ceremonia pública donde los nativos, como simples espectadores, fueron incorporados a la Corona española. ${ }^{74}$ Para legitimar y dar sentido a su presencia en las islas, los jesuitas levantaron un altar y bautizaron aquella playa como de los Mártires, por haber sido avistada el 15 de junio, día de los mártires Vito, Modesto y Crescencio, prefigurando los tristes acontecimientos que estaban por venir. ${ }^{75}$

Establecieron su base de operaciones en la localidad de Agaña, en la isla de Guam. Según las Cartas Anuas, se contabilizaron alrededor de veinte mil habitantes, trece mil de los cuales fueron bautizados aquel mismo año. La mayor parte fueron distribuidos en unos ciento ochenta pueblos dispersos en las playas y en el interior de la isla. ${ }^{76}$ Entre ellos vivía un español llamado Pedro Jiménez, que pertenecía a la tripulación de la nao «Nuestra Señora de Concepción» que naufragó en 1638 en la costa occidental de Saipán, víctima de un tifón. De su vida sabemos muy poco, excepto que tenía una hija de dos años que los jesuitas bautizaron con el nombre de Mariana. ${ }^{77}$ Otros náufragos de 1638 permanecieron en las islas el resto de sus días. Dos de ellos, los filipinos cristianos Lorenzo Malabar y Francisco Maunahun, se incorporaron desde el principio a la misión con San Vítores. ${ }^{78}$

Asimismo, uno de los jefes chamorri de mayor rango, llamado Kepuha (o Quipuha) los recibió con cordialidad, y tras bautizarse y recibir el nombre de Juan, los autorizó a predicar y bautizar en su territorio. ${ }^{79}$ Ganada así su voluntad,

74 Patricia SEED, Ceremonies of Possession in Europe's Conquest of the New World. 1492-1648. Cambridge: Cambridge UP, 1995.

75 García, 47-50, citado en Wenceslao Soto ArtuñEdo, «Luis de Medina, el jesuita extremeño, mártir de las islas Marianas», Isla de Arriarán, 21 (Junio, 2003) 83-101.

76 «Relación de las empresas y sucesos espirituales y temporales de las islas Marianas, que antes se llamaban Ladrones, desde que el año de sesenta y ocho se introdujo en ellas el Santo Evangelio por los Religiosos de la Compañía» (Real Academia de la Historia (en adelante, RAH), Fondo Cortes 567, 92676-8, f. 3v); ARSI, Philippine Historiae, 1663-1734, Tomo 13, f. 5r; Manuel de SolóRZANO, «Descripción de las islas Marianas, costumbres de sus naturales...»f. 124r). Véase también AstRAIN, Historia, Tomo VI, 812.

77 Carta de Diego Luis de San Vítores al provincial Luis de Pimentel, con fecha en Guam, 17 de junio de 1668 (RAH, Fondo Cortes 567, 9-2676/6(2), f. 1r). Otros náufragos habían ido a parar a las Marianas, como por ejemplo Gonzalo de Vigo, que había desertado de la nave de Magallanes en 1522, sirviendo como informante para la expedición que en 1526 llegó a Guam al mando del capitán Toribio Alonso de Salazar (BRUNAL-PERRY, «Las islas Marianas enclave estratégico...», 544).

78 El 5 de junio de 1672, Lorenzo murió martirizado con gran crueldad en la isla de Anatagan, adonde había ido a bautizar niños enfermos (LEDESMA, «Noticias de los progresos de nuestra Santa Fe...», ff. 10r-10v; Murillo Velarde, Historia, ff. 332r-332v; Schumacher, «Blessed Pedro Calungsod, Martyr: An Historian's Comments on His Philippine Background», 317.

${ }^{79}$ García, 47-50, citado en Soto ArtuñEdo, «Luis de Medina...»; BrunAL-PERrY, «Los misioneros españoles...», 45 .

Hispania Sacra, LXIII

128, julio-diciembre 2011, 707-745, ISSN: 0018-215-X 
San Vítores envió a los padres Morales y Cardeñoso, acompañados de varios asistentes y soldados a la isla de Tinian (agosto, 1668). ${ }^{80}$ Pero los nativos, desconfiando de sus actividades, hirieron al padre Morales en una pierna y acabaron con la vida del sargento Lorenzo Castellanos y su intérprete tagalo Gabriel de la Cruz, lo que aceleró su vuelta a Guam (octubre, 1668). Allí se recuperó de las heridas, y tras regresar a Tinian, restableció la misión. Lo acompañaba el padre San Vítores, quien utilizó la isla como una plataforma de lanzamiento para explorar las islas del norte, empezando por Saipán, hasta el Japón. ${ }^{81}$

Estos líderes pertenecían a un grupo de alto rango, más conocidos como matua, que vivían mayormente en la costa. Para ellos el prestigio y estatus de cada miembro dependía de su capacidad para acumular poder sobrenatural, o mana, que se reflejaba en los símbolos específicos que portaban -huesos, collares de conchas, etc. ${ }^{82}$ La preservación de las diferencias sociales exigía una restricción de aquellos bienes o prácticas culturales que constituían marcadores simbólicos de su identidad grupal. Así, mientras que los chamorri pretendían evitar que la «gente común»-o mangatchang- del interior de la isla participara de los sacramentos, los jesuitas querían evangelizar toda la isla de Guam, lo que provocó las primeras tensiones con los recién llegados. ${ }^{83}$ Para ello empezaron por delinear un pequeño poblado a cordel, siguiendo el modelo castellano, estableciendo los lugares más apropiados para la edificación de la iglesia del Dulce Nombre de María, fundada el 2 de febrero de 1669, la escuela y la casa de las autoridades civiles y eclesiásticas. Con estas ceremonias certificaron el acto de posesión por medio del derecho y el deber de la Corona de propagar el evangelio en ultramar y defenderlos de los enemigos herejes de las Españas. ${ }^{84} \mathrm{Y}$ desde

${ }^{80}$ Luis de Morales, SJ, Historia de las islas Marianas (ca. 1690), ff. 43; 53 (AHCJC, FIL HIS 061, E.I, c-05/2/0).

${ }^{81}$ ARSI, Philippine Historiae, 1663-1734, Tomo 13, f. 5v; Luis de Morales, Historia, ff. 43; 53.

82 Roger KeEsing, Rethinking Mana (1984), citado en Carlos Mondragón PÉREZ-Grovas, «Reflexiones historiográficas en torno a las percepciones oceánicas durante los primeros encuentros entre europeos y melanesios en el Pacífico», en Miguel LuQue TAlaván \& Marta M. Manchado López (coord.), Un océano de intercambios: Hispanoasia (1521-1898). Un homenaje al profesor Leoncio Cabrero Fernández, Tomo I, Madrid: AECI, 2008, 91. Véase también ThOMPSON, «The Native Culture of the Marianas Islands», 13.

${ }^{83}$ De acuerdo con la Historia del padre Luis de Morales, la sociedad chamorra se dividía en nobles (matua), semi-nobles o clase media (atchaot) y clase baja (mangatchang). Eran profundamente endogámicos y restringían el contacto con los demás marianos mediante ritos y tabús (ff. 29-30). Véase también Louis de Freycinet (Voyage autour du monde, 1829-1837), citado en THOMPSON, «The Native Culture of the Marianas Islands», 13-14; Augusto V. DE VIANA, «Filipino Natives in Seventeenth Century Marianas: Their role in the establishment of the Spanish mission in the islands». Micronesian. Journal of the Humanities and the Social Sciences 3:1-2 (2004) 21.

${ }^{84}$ Según la relación del padre provincial Ledesma, a finales de 1668 tres naves holandesas se aproximaron a la bahía de Umatac, en Guam, y a la isla de Zarpana o Rota (Andrés de LEDESMA, SJ, Noticia de los progresos de nuestra Santa Fe en las islas Marianas, llamadas antes de los Ladrones, y del fruto que se han hecho en ellas el padre Diego Luis de Sanvitores, y sus compañeros de la Compañía 
luego, los jesuitas habían venido a quedarse. Desde Guam extendieron su radio de acción hasta el norte y las doce islas restantes, principalmente a las más grandes y habitadas, como Saipán, bautizada como San José, Tinian, Buenavista Mariana, y Rota, conocida también como Serpana o Zerpana y bautizada como Santa Ana, al sudoeste, dando comienzo a lo que se ha dado en llamar el segundo período de la historia de las islas Marianas (16681698). 85

Los religiosos no estaban solos. En primer lugar, contaban con el apoyo de varios auxiliares de diversas etnias (los pampangos, visayas, pero también criollos y mestizos provenientes de la Nueva España) que sin ser catequistas, ayudaban a los sacerdotes en sus tareas domésticas. Otros se dedicaban a tareas evangélicas, dirigiendo las oraciones o enseñando a los niños a leer y escribir. ${ }^{86}$ En segundo lugar, se acompañaron de algunos soldados para defenderse de los ataques de los marianos, tratando de no entrometerse en los ataques a los nativos. Fundaron pueblos al más puro estilo franciscano, sin armas ni soldados, si bien los incorporaron muy pronto en sus misiones volantes..$^{87}$ No fue hasta la muerte de Luis de Medina (1670) que el Virrey de Nueva España, a petición de San Vítores, envió algunos soldados para que fueran incorporados al futuro presidio de Guam. Hasta entonces, contaban solamente con el capitán Juan de Santa Cruz Panday, su intérprete, don Francisco de Mendoza, el capitán Lorenzo Castellanos y su intérprete tagalo Gabriel de la Cruz, ${ }^{88}$ quienes, además de su

de Jesús, desde 15 de mayo de 1669 hasta 28 de abril de 1670, sacadas de las cartas que ha escrito el padre Diego Luis de Sanvitores y sus compañeros, 1670, f. 2r).

${ }^{85}$ Luis IBÁÑ̃z y GARCíA, Historia de las Islas Marianas con su derrotero, y de las Carolinas y Palaos, desde el descubrimiento por Magallanes en el año 1521, hasta nuestros días. Granada: Imprenta y Librería de Paulino V. Sabatel, 1886, 35.

${ }^{86} \mathrm{Al}$ respecto, SCHUMACHER considera que dichos auxiliares no podían ser considerados en ningún caso como catequistas, puesto que no habían escuelas para ello ( «Blessed Pedro Calungsod, Martyr: An Historian's Comments on His Philippine Background», 305). Sin embargo, en tierras de misión, donde los jesuitas no contaban con efectivos suficientes, algunos auxiliares pudieron ejercer un grado de autonomía en labores educativas y pastorales que hubiera sido impensable en otros lugares. Sea como fuere, lo cierto es que a partir de 1680 los colegiales de San Juan de Letrán eran muy aplicados. Había músicos, «que tocan muy bien el arpa y hacen con primor el oficio de catequistas cuando se lo encargan los padres» (AHCJC, Documentos manuscritos Historia de Filipinas (FILPAS), 52, 16681686$, f. $357 \mathrm{v})$.

${ }^{87}$ El provincial del Perú, José de AcosTa (1576-1581), fue uno de los firmes partidarios de las expediciones misionales protegidas por soldados (Acosta, De Procuranda Indorum Salute, Libro II, Cap. 12. Madrid: CSIC, 1984, 339-341). En Filipinas, el arzobispo riojano Domingo de Salazar se opuso a que los jesuitas evangelizaran con escoltas armadas, lo que llevó al octogenario prelado hasta Madrid para defender sus postulados, donde murió en 1594 (Molina, Historia de Filipinas, 90-91).

${ }^{88}$ El 19 de agosto de 1668 los marianos asesinaron al sargento Castellanos y a su intérprete tagalo en Tinian (García, 1683, f. 232, citado en SCHUMACHER, «Blessed Pedro Calungsod, Martyr: An Historian's Comments on His Philippine Background», 315).

Hispania Sacra, LXIII

128, julio-diciembre 2011, 707-745, ISSN: 0018-215-X 
papel como comandantes militares y marinos, apoyaban a los jesuitas en sus actividades misionales. ${ }^{89}$

Este período se caracterizó por las guerras chamorras, puntuadas por pequeños intervalos de paz. La imposición violenta de un poder soberano (entendido como un orden moral-legal) se basó en la organización de expediciones guerreras o malocas, cuyo objetivo era someter a los nativos para extraerles un beneficio en forma de prestaciones de trabajo y otros servicios. La residencia, primero, y, luego, la encomienda, se consideraron fórmulas adecuadas para pacificar los espacios de frontera del imperio colonial español. ${ }^{90} \mathrm{Si}$ bien es cierto que en las Filipinas el sistema de encomienda tenía un gran valor social y de prestigio, en las Marianas no se estableció de manera efectiva, porque los nativos estaban exentos de pagar tributo y del pago de derechos de la iglesia. ${ }^{91}$

Los primeros sargentos mayores fueron don Juan de Santa Cruz Panday (1668-72) y don Juan de Santiago Bozo (1672-74), quienes esperaban obtener alguna recompensa por sus servicios. La guerra proporcionaba medios de ascenso social, pero muy pronto se vieron decepcionados por los escasos recursos que ofrecían las Marianas. Como apuntaba el padre Murillo Velarde, «en dichas islas (San Vítores) no hallaba carne, pan, vino, ni otras cosas, de que no carecen allá ni aun los mendigos»..$^{92}$ A todo ello se unía la belicosidad de los nativos, la dificultad de aprender su lengua y el aislamiento de las islas, lo que no favoreció su colonización, correspondiendo a los misioneros la tarea de ocupar de facto las islas.

En lo eclesiástico dependían del obispado de Cebú, fundado en 1595 por el papa Clemente VIII (1592-1605), pero en la práctica los jesuitas actuaron sin ninguna visita del ordinario hasta $1682 .{ }^{93}$ El padre Medina permaneció tres me-

\footnotetext{
${ }^{89}$ El jesuita Schumacher escribió que además de soldado, don Juan de Santa Cruz Panday era sacerdote, ocupándose en bautizar y atender a los jesuitas en sus tareas misionales. Defendía, no obstante, que las actividades de Santa Cruz eran exclusivamente misionales: «it was only out of necessity that he took military command in crises» («Blessed Pedro Calungsod, Martyr: An Historian’s Comments on His Philippine Background», 321). Aunque esta combinación de sacerdote castrense ilustra perfectamente el contexto de dominación de las Marianas, lo cierto es que Santa Cruz era «maestro del hierro». Viajó a las islas acompañado de su mujer, la cual estaba destinada como maestra de las niñas, así como su hermana y su hijo de dieciséis meses (RAH, Fondo Cortes 567, 9-2676/4, f. 2r).

90 El sistema de encomienda acabó siendo abolido oficialmente en 1721. Al respecto, véase Patricio Hidalgo Nuchera, Encomienda, tributo y trabajo en Filipinas (1570-1608). Madrid: Polifemo, 1995; Hidalgo NuCHERA, «Sistemas para la explotación de las islas: encomiendas, tributos y comercio», en: Ma Dolores ElizALde PÉREZ-Grueso (eds.), Las relaciones entre España y Filipinas, 81.

${ }^{91}$ BrunAL-PERRY, «Las islas Marianas enclave estratégico...», 554.

92 Murillo Velarde, Historia, f. 328r.

${ }^{93}$ El arzobispo de Manila, el dominico fray Felipe Pardo (1677-89) nunca visitó las islas. Sus relaciones con la Compañía nunca fueron buenas. Correspondió a fray Juan Durán, obispo de Cebú (1682), efectuar la primera visita pastoral a las islas (Marjorie G. DRIVER, Cross, Sword, and Silver. The Nascent Spanish Colony in the Mariana Islands, Micronesian Area Research Center (MARC) University of Guam, 1987, 21).
} 
ses predicando en el sur de la isla de Guam, durante los cuales quemó muchos ídolos, prohibió la promiscuidad y la poligamia, bautizó a adultos y niños y enterró las calaveras de sus antepasados en el nombre de Cristo el 16 de julio de $1668 .{ }^{94}$

También promovió la devoción a la Virgen María, estableciendo las primeras congregaciones marianas en las islas Marianas. Durante las misiones populares salía con una cruz alta de plata al frente y con sus fieles en procesión, los cuales repetían las oraciones y sentencias que habían aprendido de memoria. Después de cada acto de contrición se dirigían a otro lugar para pedir a Dios bienes temporales y espirituales, finalizando la comitiva en la iglesia. ${ }^{95}$ Pero los hechiceros y chamanes (macanas, kakahnas) locales, que reverenciaban los espíritus de los antepasados, buenos y malos (anite o anitis), probablemente pensaron que los auténticos «brujos» (caníbales, comedores de carne humana) eran los jesuitas, disuadiendo a los nativos de que se bautizaran y pronosticándoles la muerte si los desobedecían. .96

Respondiendo a los deseos del provincial de las Filipinas, Miguel Solana (1668-1669), los padres San Vítores y Morales se encargaron de visitar las islas del norte, empezando por Aquigán, Tinian y Saipán. ${ }^{97}$ Su objetivo era saltar de isla en isla, buscando nativos que evangelizar. Les acompañaba la llamada Armada Naval Mariana o Escuadrón Mariano, una pequeña «flota» de tres o cuatro canoas con diez soldados, en su mayoría filipinos, comandada por el capitán Juan de Santa Cruz Panday, que disponían de tres mosquetes y una pequeña pieza de campaña. Mientras que la Historia del padre Luis de Morales hacía énfasis en los vientos y tormentas que dificultaban el acceso a las islas, los hagiógrafos jesuitas definieron aquella topografía «áspera y fragosa» como consecuencia de la resistencia feroz de los marianos, estableciendo un vínculo entre aquella «tierra de guerra»y sus habitantes «fronterizos».98 A fines de 1669 el padre Medina pasó algunas semanas en Tinian terciando entre dos bandas rivales, los habitantes de Marpo y los de Sungharon, hasta la llegada de San Vítores a finales de noviembre de 1669. Sus hagiógrafos destacaron el esfuerzo de los jesuitas (Medina, San Vítores) en favor de la pacificación de los conflic-

${ }^{94}$ LedeSMA, «Noticias de los progresos de nuestra Santa Fe...», ff. 5r-5v; Luis de Morales, Historia, ff. 48-49.

95 Broggio, «L'acto de contrición entre Europe et Nouveaux Mondes...», 248-250.

96 Según Murillo Velarde (Historia, f. 330r), «los isleños de Marianas vieron tantos prodigios, que le [San Vítores] apellidaban Macana, que significa hombre milagroso, pues parece tenía dominio en los mares, y en los vientos». El hecho no debería sorprendernos, puesto que el mundo católico creía firmemente que los santos, al igual que los diablos, contaban con poderes preternaturales capaces de controlar la naturaleza en su lucha contra el Maligno (CAÑIZARES-EsGUERRA, Católicos y puritanos..., 194-199).

${ }^{97}$ Luis de Morales, Historia, f. 62.

98 GiudicelLi, «Pacificación y construcción...», 165-166. 
tos locales. ${ }^{99}$ Para ello comprometieron públicamente a sus líderes a olvidar los resentimientos mediante parlamentos y acuerdos de paz en los que el aparato ceremonial/simbólico era fundamental. Como señala Broggio, este modelo de mediación no era nuevo, sino que tenía que ver con las estrategias de pacificación llevadas a cabo por los jesuitas en las misiones «populares» de la Europa católica. ${ }^{100}$ En las misiones fronterizas del Pacífico, los religiosos se constituyeron en autoridades morales capaces de garantizar un estado de paz y bienestar. De la misma forma, existía también un interés por parte de los panegiristas, como el padre provincial Andrés de Ledesma (1671-75), 101 en presentarlos como víctimas del abuso y crueldad de los indios de guerra, quienes a menudo los apedreaban y los alanceaban. ${ }^{102}$ Pero lo cierto es que fueron los jesuitas quienes se interpusieron en un conflicto entre dos facciones rivales con el fin de proteger el fruto obtenido. ${ }^{103}$

El 24 de enero de 1670, después de conseguir una reconciliación entre los dos pueblos, se levantó una pequeña ermita en honor de Nuestra Señora de la Paz.104 Allí permanecieron los soldados por espacio de dos meses, en los que se reanudaron los conflictos. Murió uno de los tagalos auxiliares de poco más de doce años, de nombre Andrés de la Cruz, mientras que un mestizo o criollo -«españolito»natural de México, llamado Diego Bazán, fue herido. ${ }^{105}$ Si sobre el terreno estos misioneros jesuitas actuaron como pacificadores, se podría decir que sus panegiristas y superiores construyeron a los marianos en un grupo étnico enemigo.

El 27 de enero de 1670, el padre Medina fue a visitar la isla de Saipán, certificando que la predicación había sido muy epidérmica. La curiosidad inicial se transformó en sospecha y abierta hostilidad cuando advirtió que la influencia

99 LEDESMA, «Noticias de los progresos de nuestra Santa Fe...», f. 8r; FlorENCIA, Ejemplar vida y dichosa muerte..., ff. 36-42; Francisco GARcíA, SJ, Relación de la Vida de el devotísimo hijo de María Santísima, y dichoso Mártir Padre Luis de Medina de la Compañía de Jesús, que murió por Cristo en las Islas Marianas (llamadas antes de los Ladrones) con otro Compañero seglar llamado Hipólito de la Cruz, Madrid, Imprenta de Juan García Infanzón, 1673, ff. 96, 255-56.

100 Paolo Broggio, «I gesuiti come mediatori nella guerra d'Arauco: il padre Luis de Valdivia e il sistema dei parlamentos de indios (XVII secolo)». Archivum Historicum Societatis Iesu LXXIV: 147 (2005) 57-89.

${ }^{101}$ El padre Andrés de Ledesma nació en Cartagena el 16 de enero de 1610. Entró en la Compañía de Jesús el 6 de diciembre de 1627. Era graduado y profeso de cuatro votos (7/12/1650) (ARSI, «Primus Catalogus Anni Personarum Anni 1672». Philippinae Cat. Trien. 1649-1696, Tomo 2-II, f. 360r).

102 LEDESMA, «Noticias de los progresos de nuestra Santa Fe...», ff. 8r-9r.

103 Luis de Morales, Historia, ff. 65-68.

104 Ibidem, f. 68.

105 Andrés de la Cruz era cantor («niño tiple») y ayudaba comúnmente en la sacristía (RAH, Fondo Cortes 567, 9-2676/4, f. 2r). El capitán Diego Bazán murió poco después, el 31 de marzo de 1671 (RAH, Fondo Cortes, 567, 9-2676/8, f. 28v; ARSI, «Noticias de las islas Marianas enviadas el año de 1670», con fecha 22 de abril de 1670, Philippinae Historiae, 1663-1734, Tomo 13, f. 50r; LEDESMA, «Noticias de los progresos de nuestra Santa Fe...», f. 9r. 
del «sangley pervertidor de los marianos» había llegado hasta allí. ${ }^{106}$ Choco, que así se llamaba, era el capitán de una embarcación china que naufragó veinte años antes de la llegada de los jesuitas a Guam. Se asentó en la zona de Merizo, al sudoeste de la isla, y como partidario de los bonzos (o monjes) budistas gozaba de influencia y prestigio entre los marianos. ${ }^{107}$ Estaba casado con una mujer de Saipán, y desde la llegada de los españoles empezó a propagar la historia de que «el padre derramaba enfermedades con el agua y los santos óleos que echaba a los niños y ancianos», causándoles la muerte.

En su hagiografía ejemplar sobre el protomártir Medina, el padre Florencia aseguraba que la Virgen se apareció en sueños a un indio cristiano de Saipán. Se trataba de una escena maternal en la que la Purísima cuidaba de ocho niños mayores mientras amamantaba a otros dos más pequeños. Pero además, portaba al Can Cerbero atado a sus pies en una alegoría victoriosa del Bien sobre el Mal, «en beneficio de aquellos inocentes niños al perverso Sangley, que tanto había ladrado en perjuicio suyo».108

Con tan poderosa aliada, el jesuita empezó sus tareas evangelizadoras bautizando a los niños, especialmente aquellos que se encontraban enfermos o moribundos. A pesar de su notoria cojera y tartamudez, su fervor mesiánico lo llevó a actuar con gran determinación, arrancándoles los huesos y amuletos que llevaban, considerándolos como formas idolátricas de adoración. ${ }^{109}$ Para los jesuitas, esta nueva identidad sacramental exigía la total aceptación de Dios y de su omnipotencia divina, utilizando para ello el poder taumatúrgico de las reliquias de sus santos patronos (San Ignacio, San Francisco Javier). ${ }^{110}$ Al prometer un nuevo universo de salvación se establecieron relaciones de dependencia a través de los cuales los nativos, como pecadores, quedaban supeditados a la voluntad de la iglesia y sus representantes. Como ha señalado Vicente Rafael, las contraprestaciones en forma de tributos, trabajo o lealtad sacramental era la única forma de saldar la deuda contraída con los españoles. ${ }^{111}$

106 FLORENCIA, Ejemplar vida y dichosa muerte..., f. 30v.

${ }^{107}$ Luis de Morales, Historia, f. 51; RAH, Fondo Cortes, 567, 9-2676/8, f. 6r; ARSI, Philippine Historiae, 1663-1734, Tomo 13, f. 5r-8r.

108 FLORENCIA, Ejemplar vida y dichosa muerte..., 1673, f. 43r.

109 AHCJC, Carpeta «EI.b-9/5/2. Martirios, naufragios, \&.», contenida en EI/b-9/5/1-7. «Martirios y varones ilustres». Portada. LII. Juan de Santa Cruz, «Más sobre la vida y martirio del padre Luis de Medina. 22 de mayo de 1670, f. 8. Existe un traslado de esta carta martirial en AHCJC, Historia Missionis, Tomo III, y titulado «Copia de documentos antiguos del Archivo de la Misión de la Compañía de Jesús, nº 1», Signatura Antigua: E.I., a-13 (1593-1890), ff. 604-615.

110 Manuel de SolóRzano, «Descripción de las islas Marianas, costumbres de sus naturales...», f. $127 \mathrm{r}-131 \mathrm{r})$.

111 Un excelente análisis de los mecanismos de conversión en la sociedad tagala se encuentra en Vicente L. RAFAEL, Contracting Colonialism: Traslation and Christian Conversion in Tagalog Society Under Early Spanish Rule, Ithaca, Cornell UP, 1988, 88-109.

Hispania Sacra, LXIII

128, julio-diciembre 2011, 707-745, ISSN: 0018-215-X 
Pero los marianos no eran objetos pasivos de la conversión misionera. Creían que Medina y sus auxiliares seglares, Agustín e Hipólito de la Cruz, mataban a los niños y se los comían. Dos días más tarde el padre Medina fue asesinado en la tercera aldea que visitaba por un tal Poyo, a quien los marianos llamaban «el matador», luego bautizado como Luis, y su cómplice, llamado Daon, bautizado como Vidal. ${ }^{12}$ Con él murió Hipólito de la Cruz, natural de las islas de los Pintados o Visayas (Cebú) y virtuoso del harpa, con cuya música trataba de apaciguar a los «salvajes».113 Estos martirios obligaron al superior San Vítores a solicitar nuevos misioneros de Austria y de otras partes para las Marianas. ${ }^{114}$

Mientras tanto, el 22 de mayo de 1670, después de haber ido a rescatar los restos del padre Medina y su auxiliar, el capitán don Juan de Santa Cruz Panday escribió una Relación acerca de la muerte heroica del jesuita. Para perpetuar su memoria elaboró un programa de exaltación martirial, mostrando a los fieles la tragedia de la sangre y la fidelidad de la Compañía a la misión. Este corpus hagiográfico se basaba en una retórica de santidad que vertebraba ideológicamente a los jesuitas con la sociedad colonial. ${ }^{115} \mathrm{El} 26$ de abril de 1670, acompañado de un principal del pueblo de Cao, subió al monte más alto y puso simbólicamente dos cruces. Luego condujo los restos mortales, primero a Tinian, y luego a Agaña, en Guam, donde fueron solemnemente enterrados debajo del altar mayor. Desplegados por el territorio mariano, los símbolos martiriales, como formas de posesión, sirvieron para consolidar la presencia española en las islas. ${ }^{116}$

Hubo otras representaciones plásticas para cohesionar a los jesuitas como un cuerpo misionero. En marzo de 1671 trajeron desde Nueva España una imagen de Francisco Javier. Lo veneraban por ser uno de los padres fundadores de la orden, pero además, por haber sido uno de los misioneros ejemplares que había tenido la Compañía en Asia. Era un espejo en el que se reflejaron algunos de los primeros misioneros, como los padres Medina y San Vítores. ${ }^{117}$ De su media-

112 Según la lista de mártires, murió «in odium sacram baptismati et fidei christianae praedicationis a barbari» (AHCJC, Carpeta «EI.b-9/5/2. Martirios, naufragios, \&.», contenida en EI/b-9/5/1-7. «Martirios y varones ilustres». Hojas sueltas).

113 En la carta que escribió San Vítores al procurador José Vidal Figueroa, con fecha en Guam, 21 de mayo de 1671, le solicitaba «todo género de instrumentos músicos, arpas, guitarras, liras, cornetas y todos los demás instrumentos que pertenecen a la música con algunos libros de punto. Además, pedía un órgano y organista para los niños pudieran aprender las habilidades musicales (AstraIN, Historia, Tomo VI, 817).

114 AHCJC, «Relación y documentos referentes a las islas Marianas, 1668-1673». FILPAS (Colección Pastells), 52, f. 341r.

115 Para una lectura de lo «hagiográfico» como género literario, véase Norma DuRÁN, Retóricas de la santidad. Renuncia, culpa y subjetividad en un caso novohispano, México: Universidad Iberoamericana, 2008.

116 «Más sobre la vida y martirio del padre Luis de Medina». (AHCJC, EI.b-9/6, ff. 1-13).

117 Murillo Velarde, Historia, ff. 327v. 
ción se esperaban grandes cosas. Por esas fechas acaeció un tifón que arrancó árboles y destruyó las casas y haciendas de los conjurados, dejándolos sin habitación ni comida. Los misioneros interpretaron esto como un signo de los atributos naturales de los santos, pero los makahnas culparon a los recién llegados de todos sus males. Desde los tiempos antiguos habían sido los encargados de invocar las lluvias o las tormentas, de arrojar maleficios o curar enfermedades.

Los muertos eran enterrados bajo las casas familiares, latte, o en cuevas, para proteger a los vivos. ${ }^{118}$ Pero ahora, la llegada de los nuevos «chamanes», con sobrepelliz, cirios y cruces, cuestionaba su poder, convirtiéndolos en enemigos declarados de sus propios paisanos. ${ }^{119}$ La misma magia cristiana, en forma de conjuros y talismanes, cruces, imágenes, acabó transformando los amuletos de los chamanes, calaveras, en imágenes falsas, ídolos, inspirados por el Demonio que habían de ser destruidos. ${ }^{120}$

Se estableció una separación radical entre los vivos y los muertos, siendo estos últimos enterrados en las iglesias o cementerios adyacentes. Pero los indios marianos reaccionaron y el 23 de julio de 1671, el mozo auxiliar, José Peralta, nacido en la Puebla de los Ángeles y compañero del padre provincial San Vítores, murió a causa de de 18 heridas recibidas en una emboscada por los seguidores del jefe Hurao, uno de los líderes locales o m'agas de Agaña, cuando iba a cortar madera para labrar las cruces con las que coronar las casas de los nuevos cristianos. ${ }^{121}$ El empleo de estos símbolos cristianos (cruces, imágenes) por parte de los católicos recién convertidos no sólo establecía una frontera entre el territorio cristiano y el pagano, sino que además funcionaba como un talismán frente al poder de los demonios. ${ }^{122}$ Los soldados españoles reprimieron la agresión matando al indio principal Huasac. Eso provocó un gran levantamiento conocido como la «Primera Gran Guerra de Guam» (11/09/1671). ${ }^{123}$

Durante ocho días, uno de los jefes marianos, de nombre Hurao, ordenó el asedio de la empalizada que los españoles habían improvisado alrededor de la iglesia y casa de los jesuitas. En las refriegas el líder Hurao fue apresado, lo que provocó una negociación entre ambos bandos que llevó a su liberación. Con este gesto San

118 ThOMPSON, «The Native Culture...», 25-27.

119 Luis de Morales, Historia, f. 77.

${ }^{120}$ Sobre la religión chamorra, véase THOMPSON, «The Native Culture...», 20-23.

${ }^{121}$ ARSI, «Historica narratio illorum (1668-1673), Filipinas Tomo 13, fol. 95-110, citado en Rodrigue LÉVESQUE (eds.), History of Micronesia. A Collection of Source Documents. Vol. 6 - European Discovery (1521-1560), Québec, Gatineau: Lévesque Publications, 1995, 47.

122 CAÑ̃IZAREs-Esguerra, Católicos y puritanos..., 154.

123 Joseph Vidal Figueroa, SJ, Carta escrita en la ciudad de México por el padre Joseph Vidal, de la Compañía de Jesús, Procurador de las Islas Marianas, a D. Gerónimo Sanvitores de la Portilla y Relación de la dichosa muerte del Venerable Padre Diego Luis de Sanvitores, Caballero del Orden de Santiago, del Consejo de su Majestad en el Real de Hacienda, 1674, ff. 2v-3r.

Hispania Sacra, LXIII

128, julio-diciembre 2011, 707-745, ISSN: 0018-215-X 
Vítores esperaba congraciarse con los líderes locales, o ma'gas, y obtener la paz. ${ }^{124}$ Pero como ya señaló el padre Morales, los marianos eran expertos «en el arte de ocultar sus intenciones». ${ }^{125}$ Así, el 31 de septiembre los marianos reanudaron sus ataques. Para contrarrestar los mosquetes y el fuego enemigo recurrieron a la magia, rodeando el fuerte con las calaveras de sus macanas, en un intento de exorcizar los poderes de sus antepasados. Pero fue en vano. El 20 de octubre de 1671 se rindieron ante la evidente superioridad de las fuerzas invasoras. ${ }^{126}$

Preocupado por los ataques que los marianos indómitos, poco o nada cristianizados, efectuaban a los recién convertidos, San Vítores escribió a la corte solicitando la construcción de un presidio militar en las Marianas (septiembre-octubre, 1671).127 Había escasez de armas, las instalaciones eran inadecuadas y los efectivos, insuficientes. ${ }^{128}$ Parecía indudable que la hegemonía española en aquellas islas dependía de la implicación directa de la Corona en su defensa. La existencia de fuertes fronterizos era la única garantía de seguridad de las misiones puesto que la mayoría de los pueblos no estaban fortificados. ${ }^{129}$

${ }^{124}$ Luis de Morales, Historia, ff. 83-84. Carlo GINZBURG recogió la «voz» de Hurao atribuyéndola erróneamente al historiador Charles Le Gobien (Carlo GINZBURG, «Alien Voices. The Dialogic Element in Early Modern Jesuit Historiography», en Hitory, Rhetoric, and Proof. The Menace Stern Jerusalem Lectures, Hannover \& London: Brandeis UP \& Historical Society of Israel, 1999, 71-91). Sin embargo, no se trataba de Le Gobien (1653-1708), sino del padre Luis de Morales, autor de la Historia de las islas Marianas que editó el jesuita francés en 1700. Al respecto, véase Luis de MoRALES, Historia de las islas Marianas. Edición, trascripción e introducción a cargo de Alexandre CoELLo (manuscrito).

125 Luis de Morales, Historia, f. 32.

126 Vidal FigueroA, SJ, Relación de la dichosa muerte del Venerable Padre Diego Luis de Sanvitores, f. $3 \mathrm{v}$.

127 Según Francisco de Vitoria, la «guerra justa» solamente se podía justificar en caso de defensa de los indios recién convertidos y a los cuales no se los podía abandonar a su suerte entre paganos hostiles (Francisco de ViTORIA, Relectio de Indis, Madrid, CSIC, [1537] 1989, 105).

128 En la carta que el procurador de los jesuitas, Joseph Vidal Figueroa, SJ, escribió al padre de Diego Luis de San Vítores, don Jerónimo, afirmaba que junto a los diez jesuitas había solamente doce españoles y diecisiete indios filipinos (Relación de la dichosa muerte del Venerable Padre Diego Luis de Sanvitores, f. $2 \mathrm{v}$ ). Al respecto, el historiador SCHUMACHER ha señalado que de los treinta o treinta y un españoles que había en las islas, apenas doce eran soldados regulares, cuestionando así las tesis de DrIVER (Cross, Sword, and Silver...), basadas en los trabajos clásicos de Ibáñez (Historia de las islas Marianas...), acerca de la existencia de un número mayor de efectivos militares bajo las órdenes de los religiosos (SCHUMACHER, «Blessed Pedro Calungsod, Martyr: An Historian's Comments on the Mission in the Marianas», 478-79). Frente a la necesidad de una fuerza militar de contención, el 22 de febrero de 1672, los jesuitas solicitaron el envío de unos 200 «hombres», entre españoles y pampangos, así como un cabo español «de la piedad y prudencia del capitán Antonio Nieto» (ARSI, «Apuntamientos de lo que parece más necesario al presente estado de estas islas Marianas según la Relación que va aparte de los sucesos», Philippinae Historiae, 1663-1734, Tomo 13, ff. 74r-74v).

129 Beatriz VITAR, Guerra y misiones en la frontera chaqueña del Tucumán (1700-1767). Madrid: CSIC, 1997, 102-110; Bernd HAUSBERGER, «La conquista jesuita del noroeste novohispano». Memoria Americana. Cuadernos de Etnohistoria 12 (2004): 131-168. 
Las peticiones del padre San Vítores $(1669,1670)$ parecían haber dado sus frutos. El 9 de junio de 1671 el galeón «Nuestra Señora del Buen Socorro» llegó al puerto de Umatac, en Guam, con nuevos misioneros (los padres Francisco de Solano ${ }^{130}$ y Diego de Noriega ( $\left.i-1672\right)$, asignados a Agaña; Francisco Ezquerra, asignado a Rota, el cartógrafo Alonso López (1646-1675),131 enviado a Tinian), soldados y provisiones, que rápidamente se vio que eran insuficientes. ${ }^{132}$ La supuesta docilidad de los nativos había sido una ilusión. $\mathrm{Ni}$ aquellas islas eran las legendarias Ofir y Tarsis ni los marianos vivían en la Edad de Oro de los antiguos. Esa imagen de una Arcadia idílica, si alguna vez existió en la mente de San Vítores, fue sustituida por visión pesimista de maldad y violencia. ${ }^{133}$ El universalismo religioso de los jesuitas, basado en el deber moral de iluminar al inocente y castigar al apóstata, acabó considerando a los habitantes de las Marianas como cristianos potenciales pero que había que doblegar.

Las resistencias eran muchas y continuadas. Los marianos se organizaban en clanes integrados por familias extensas de filiación matrilineal. Vivían en pequeños pueblos, songsong, compuestos de 50 o 150 cabañas. ${ }^{134}$ La solidaridad entre los miembros de los distritos era considerable, pero también la rivalidad que existía entre los jefes locales, como Hurao, Quipuha o el mismo Choco. Sus primeras víctimas fueron los jesuitas, especialmente sus auxiliares, porque los obligaban a vivir concentrados en pueblos y ayudaban a los sacerdotes en el bautismo y predicación del evangelio. En enero de 1672, poco después de la primera guerra de Guam (septiembre-octubre de 1671), el padre San Vítores decidió erigir cuatro iglesias o misiones, adscribiendo cuarenta pueblos a cada una de ellas. Entre el 31 de marzo y el 2 de abril de 1672 murieron los cuatro filipinos, Nicolás de Figueroa, Damián Bernal, Manuel de Nava y Pedro Ca-

${ }^{130}$ El padre Francisco Solano nació en Plasencia el 4 de octubre de 1635. Entró en la Compañía de Jesús el 1 de setiembre de 1655 (ARSI, «Primus Catalogus Anni Personarum Anni 1671». Philippinae Cat. Trien. 1649-1696, Tomo 2-II, f. 352v).

131 Alonso López nació en Plasencia el 16 de Julio de 1646. Entró en la Compañía de Jesús el 30 de septiembre de 1662. Fue operario de indios en las islas Marianas desde 1672 hasta 1675, donde murió (ARSI, «Primus Catalogus Anni Personarum Anni 1672». Philippinae Cat. Trien. 1649-1696, Tomo 2II, f. 363v).

132 ARSI, «Historica narratio illorum (1668-1673), Filipinas Tomo 13, fol. 95-110, citado en LÉVESQue, History of Micronesia, Vol. 6, 1995, 47-48. A su vez, los padres Morales y Casanova, y el hermano Bustillos regresaron a Manila a terminar sus estudios (Astrain, Historia, Tomo VI, 816).

${ }^{133}$ En 1670, San Vítores escribía que para colonizar las islas hacía falta muy pocos efectivos «entre aquella gente tan amigable y sencilla y sin armas de consideración ni borracheras que los saquen de su paz y juicio» (AHCJC, «Memoria de Diego Luis de San Vítores sobre los medios para llevar a cabo la misión en los Ladrones. 1670», FILPAS (Colección Pastells), 52, ff. 131r-131v).

134 Ledesma, «Noticia de los progresos de nuestra Santa Fe...», ff. 3v-4v. Véase también Alice Joseph \& Veronica F. Murray, Chamorros and Carolinians of Saipan. Personality Studies, Westport. Connecticut: Greenwood Press, Publishers, [1951] 1971, 15; THOMPSON, «The Native Culture...», 11.

Hispania Sacra, LXIII

128, julio-diciembre 2011, 707-745, ISSN: 0018-215-X 
lungsod Bisaya, ${ }^{135}$ traídos de Manila y Nueva España por el padre San Vítores. Y a continuación, los marianos asesinaran al «jefe» de los invasores extranjeros. ${ }^{136} \mathrm{El}$ dos de abril de 1672, el padre Luis de San Vítores se hallaba bautizando a una niña de nombre María Assión en la playa de Tumón, en la isla de Guam. Allí murió a manos de un jefe chamorro apóstata llamado Matapang (o Mata'pang), quien le atravesó el pecho con su lanza, mientras otro, de nombre Hurao, le abría la cabeza con una cimitarra. ${ }^{137}$

El Virrey de Nueva España había enviado el galeón «San Diego» al mando del almirante don Leandro Coello que transportaba un pequeño contingente militar compuesto de dieciocho soldados con armas, pólvora y munición para edificar el presidio. ${ }^{138}$ A primeros de mayo llegaron a Guam y fue allí donde tuvieron noticia de la muerte del padre San Vítores. A ellos les correspondía castigar con mano dura a los culpables. Así, el 17 de mayo de 1672, el capitán Juan de Santiago y su escuadrón, de trece arcabuceros españoles y ocho filipinos, salieron para Tumón, quemando casas, destrozando embarcaciones e hiriendo y matando a varios marianos. Las represalias se configuraban como el equivalente a la justicia, lo que legitimaba la violencia y crueldad contra los marianos. Pero en los años posteriores murieron otros tantos jesuitas y algunos de sus auxiliares y ayudantes, y varios soldados españoles y filipinos pampangos ocupados de mantener viva la presencia española en las islas. ${ }^{139}$

Tras la muerte de San Vítores, los jesuitas enviaron relaciones informativas acerca de su heroica muerte a Madrid y a Roma para activar el proceso de beatificación. ${ }^{140}$ Entretanto, en la isla de Guam, concentraron sus esfuerzos en bautizar a los niños y educarlos cristianamente. A mediados de 1669 habían edificado un pequeño colegio en la isla de Guam, pero en septiembre de 1671 un tifón había dado al traste con el proyecto. No fue hasta 1674 que se fundó

135 Para más información sobre la vida de este auxiliar de las Visayas, beatificado por el papa Juan Pablo II el 5 de marzo de 2000, véase DE LA CORTE Y RUANO, Memoria descriptiva e histórica, 19; MoJARES, «The Epiphany of Pedro Calungsod...», 34-61; SCHUMACHER, «Blessed Pedro Calungsod, Martyr: An Historian's Comments on His Philippine Background»; Schumacher, «Blessed Pedro Calungsod, Martyr: An Historian's Comments on the Mission in the Marianas».

${ }^{136}$ AHCJC, Carpeta «EI.b-9/5/2. Martirios, naufragios, \&.», contenida en EI/b-9/5/1-7. «Martirios y varones ilustres». Hojas sueltas.

137 ARSI, «Historica narratio illorum (1668-1673), Filipinas Tomo 13, f. 95-110, citado en LÉVESQue, History of Micronesia, Vol. 6, 1995, 52-53; VidAl FigueroA, SJ, Relación de la dichosa muerte del Venerable Padre Diego Luis de Sanvitores, f. 4r; Murillo Velarde, Historia, f. 332r; AsTRAIN, Historia, Tomo VI, 820.

138 Vidal FigueroA, SJ, Relación de la dichosa muerte del Venerable Padre Diego Luis de Sanvitores, f. 4v; «Relación de los sucesos de las islas Marianas desde el año de 1673 hasta mayo de 1674», AGI, citado en Astrain, Historia, Tomo VI, 816-17.

139 Murillo Velarde, Historia, ff. 332r-333r.

${ }^{140} \mathrm{Al}$ respecto, véase VIDAl FigueroA, SJ, Carta escrita en la ciudad de México por el padre Joseph Vidal..., y la Relación de su dichosa muerte..., México, 10 de febrero de 1674. 
oficialmente el colegio o seminario de niños de San Juan de Letrán, situado dentro de los muros del presidio. ${ }^{141}$ Fue un centro de enseñanza primaria, que nació con la esperanza de que los hijos más pequeños de los principales pudieran influir en sus padres y hermanos y se convirtieran al catolicismo. ${ }^{142}$ Para los religiosos, los marianos eran como niños que debían ser tutelados para evitar que siguieran practicando sus idolatrías abierta o incautamente.

Pero no era tarea fácil. A primeros de mayo de 1672 las negociaciones de paz se rompieron, dando lugar a nuevos enfrentamientos que se prolongaron hasta finales de agosto. El 5 de junio los marianos acabaron con la vida de Francisco Maunahan y Juan Marinduque, compañeros seglares del padre Alonso López en la isla de Tinian, y pocos días después, cayó enfermo el padre superior Francisco de Solano (1635-1672), falleciendo el 17 de junio víctima de una afección que contrajo en Manila. ${ }^{143}$

Tras la muerte del padre Solano los marianos todavía contemplaban a los jesuitas como enemigos, lo que se tradujo a primeros de febrero de 1674 en el asesinato del padre superior Francisco Ezquerra (1644-1674), ${ }^{144}$ natural de Manila, junto con sus cinco compañeros seglares, los filipinos Sebastián de Ribera y Luis de Vera Picazo, y los mexicanos Pedro Alejo, Matías Altamirano y Mar-

${ }^{141}$ El colegio de San Juan de Letrán se mantuvo hasta 1899 (Astrain, Historia, Tomo VI, 817; Maritza R. DEL PRIORE, Education on Guam during the Spanish Administration from 1668 to 1899, Tesis Doctoral, University of Southern California, 1986, 29-31). En 1674 se fundó un colegio de niñas bajo la advocación de Santa Rosa de Lima. Al respecto, véase ARSI, «Relación de las empresas y sucesos espirituales y temporales de las islas Marianas», Philipinae Historiae, 1663-1734, Tomo 13, f. 181v.

${ }^{142}$ Francisco Javier ya había señalado la importancia de valerse de los niños como la mejor manera de sembrar la semilla del proselitismo. El padre Morales lo confirma, subrayando que «estos niños se prestaban ellos mismos para el servicio de la Iglesia, cantaban todos los días a dos coros de la doctrina cristiana con una modestia que encantaba e iban por las calles con la campanilla en la mano para llamar a los otros niños a que acudiesen al cristianismo» (Luis de Morales, Historia, ff. 53; 57).

143 «Historica narratio illorum (1668-1673), ARSI, Filipinas Tomo 13, ff. 95-110, citado en LÉvESQUE, History of Micronesia, Vol. 6, 1995, 66-67; Luis de Morales, Historia, f. 109. Tras la muerte de San Vítores, el padre Solano se había encargado de ejercer como superior interino hasta su muerte el 17 de junio de 1672, siendo sustituido por el padre Francisco Ezquerra (Murillo Velarde, Historia, ff. 333-334; Astrain, Historia, Tomo VI, 822). Para una pequeña semblanza del padre Solano, véase Murillo Velarde, Historia, ff. 331-333.

${ }^{144}$ El padre Francisco Ezquerra llegó a las Marianas en 1671 desde Manila. Era hijo del General don Juan de Ezquerra y de doña Lucía Sarmiento. Su tío, el padre provincial Domingo Ezquerra (16011670), fue quien envió al padre San Vítores a las Marianas. Su hermano, el padre Juan Ezquerra, también era miembro de la Compañía. A la muerte del padre Solano fue nombrado superior de la misión de las Marianas, pero murió poco después, en martirio, el 2 de febrero de 1674, a los 30 años de edad, víctima de los golpes recibidos por un grupo de indios marianos en una playa de la isla de Guam (AHCJC, Carpeta «EI.b-9/5/2. Martirios, naufragios, \&.», contenida en EI/b-9/5/1-7. «Martirios y varones ilustres». Archivo Provincial de los Jesuitas de Cataluña. Hojas sueltas. Véase también Luis de MoRALES, Historia, ff. 119-121; Murillo Velarde, Historia, ff. 334-336).

Hispania Sacra, LXIII

128, julio-diciembre 2011, 707-745, ISSN: 0018-215-X 
cos de Segura -en la isla de Guam. ${ }^{145}$ Los misioneros, asustados, no se atrevían a salir del presidio por miedo a las represalias. Afortunadamente, el 16 de junio llegó a las Marianas la nao de Acapulco con una nueva expedición compuesta de cuatro padres, todavía novicios (Pedro de Ahumada, Jacinto de Montenegro, Francisco Gayoso, Sebastián de Monroy), dos hermanos estudiantes (Augusto García y Pedro Díaz) y dos hermanos legos (Pedro Pavón y Joseph de Salazar), lo que contribuyó a levantar los ánimos de la misión. ${ }^{146}$

La llegada de nuevos contingentes materiales y humanos fue aprovechada para castigar a los sediciosos. El 26 de julio de 1674, el capitán y sargento mayor del presidio, don Damián de Esplana (1674-76), un veterano criollo de las guerras de Chile,147 acompañado del padre Alonso López, tomó a su cargo un escuadrón compuesto de 30 soldados que acababan de llegar a las islas y quemó diversas rancherías hasta llegar al pueblo de Chuchugu, «que estaba situado en lo alto de una montaña», estableciendo alianzas con algunos indios principales, como don Diego Aguarin (o Agua'lin), con los que consiguió extender su radio de acción y construir pequeñas iglesias y escuelas en los pueblos de Francisco Javier de Ritidian, San Miguel de Tarragi y Tupungan. ${ }^{148}$

145 «Carta del padre Coomans al padre Norbertus Van Coukerken, con fecha en Agaña, 10 de mayo de 1674» («Historica narratio illorum (1668-1673), ARSI, Filipinas Tomo 13, ff. 95-110, citado en LÉVESQUE, History of Micronesia, Vol. 6, 1995, 153-155); «Carta del padre Coomans al padre Lawrence Van Schoonen, con fecha en Agaña, 10 de mayo de 1674» («Historica narratio illorum (1668-1673), ARSI, Filipinas Tomo 13, ff. 95-110, citado en LÉvESQue, History of Micronesia, Vol. 6, 1995, 159160). Véase también Luis de Morales, Historia, ff. 115-119; Murillo Velarde, Historia, ff. 333v334 .

146 En dicha nave se embarcó el hasta entonces superior de la misión, el padre Pedro Coomans. No fue una operación fácil. Los fuertes vientos la obligaron a alejarse de la costa, dificultando enormemente el desembarco de los misioneros y los bastimentos Con ellos iba don Damián de la Esplana, nombrado gobernador de las Marianas («Relación de las empresas y sucesos espirituales y temporales de las islas Marianas, que antes se llamaban Ladrones, desde que el año de sesenta y ocho se introdujo en ellas el Santo Evangelio por los Religiosos de la Compañía». RAH, Fondo Cortes, 567, 9-2676-8, ff. 45v-46r). Véase también Luis de Morales, Historia, ff. 121-122; Murillo Velarde, Historia, f. 340v; Astrain, Historia, Tomo VI, 822-23.

147 Don Damián de la Esplana (1641-1694) era peruano y sirvió durante 23 años en las guerras de Chile. Estaba casado con doña Josefa de León Pinelo, hija de una de las familias criollas más prominentes del Virreinato del Perú (ARSI, «Relación de las islas Marianas desde el mes de junio de 1674 hasta 1675», Philipinae Historiae, 1663-1734, Tomo 13, f. 121r; DRIVER, Cross, Sword, and Silver, 15). En 1674 don Diego de Arévalo, general del galeón «Nuestra Señora del Buen Socorro», lo nombró para el cargo de gobernador de las Marianas. Murió en agosto de 1694, víctima de hidropesía (AsTRAIN, Historia, Tomo VI, 825; 832). Véase también Francis X. HeZEL, SJ, «From conversion to conquest», The Journal of Pacific History 17 (1982), 127.

148 ARSI, «Relación de las islas Marianas desde el mes de junio de 1674 hasta 1675», Philipinae Historiae, 1663-1734, Tomo 13, ff. 121r-127v; Luis de Morales, Historia, f. 123; «Carta del padre Coomans al padre Libertus De Pape, con fecha en Agaña, 30 de mayo de 1679» (LÉVESQue, History of Micronesia, Vol. 7, 1996, 47-54). Véase también Murillo Velarde, Historia, f. 335v. 
Tras las últimas entradas militares, los nativos parecían haberse sosegado. A juzgar por la Relación de las islas Marianas de finales de junio de 1675, el ambiente era de optimismo. ${ }^{149}$ El 10 de junio de 1675 el galeón «San Telmo» había desembarcado 14 soldados, cuatro nuevos jesuitas y un hermano coadjutor en Guam. Dos de ellos, los padres Gerardo Bowens ${ }^{150}$ y Lorenzo Bustillo, ${ }^{151}$ se ocuparon de relanzar el proyecto misionero y educacional a través de la lectura y comentario de textos sagrados, la prédica y el sermón, la confesión y la absolución. Pero ese optimismo se tornó en desilusión a causa del capitán Esplana, cuyas intenciones eran relegar a los jesuitas a la doctrina cristiana, obteniendo así la jurisdicción política y criminal de la misión. El padre superior San Basilio protestó enérgicamente, aduciendo sus derechos a «gobernar las armas». 152 Pero sus protestas no tuvieron ningún efecto. El capitán les obligó a erigir dos colegios dentro del presidio, uno de niños, dedicado al Ángel de la Guarda, y otro de niñas, consagrado a Rosa de Lima, donde vivían en régimen de internado mientras aprendían a leer y escribir, participaban de la misa y cantaban en el coro. También había clases de catecismo («leer la cartilla»), a base de preguntas y respuestas, que dirigían los padres y auxiliares mejor preparados e instruidos. ${ }^{153}$

La fundación del colegio o casa de niñas respondía a la imposición de un modelo patriarcal en la organización de la vida comunitaria de la misión, la cual no estaba exenta de polémica. En primer lugar, porque los soldados entraban por la noche y seducían a las muchachas que dormían en el colegio. Para evitarlo, el padre superior ordenó a dos religiosos durmiesen dentro de la misma casa de las niñas, las cuales ocupaban una estancia aparte, bajo llave, lo que paradójicamente no evitó que continuasen los escándalos. ${ }^{154}$ En segundo lugar,

149 «Relación de las islas Marianas desde el mes de junio de 1674 hasta junio de 1675» (ARSI, Philippinae Historiae, 1663-1734, Tomo 13, ff. 121r-127v). Véase también Astrain, Historia, Tomo VI, 823 .

${ }^{150}$ El 2 de febrero de 1675, el padre Bowens fue nombrado profeso de cuatro votos en la Casa Profesa de la ciudad de México ( «Carta del padre Bowens al padre Libertus de Pape, con fecha en México, 28 de febrero de 1675», en LÉVESQUE, History of Micronesia, Vol. 6, 1995, 266-270).

151 Mientras estuvo en la Nueva España (1675), Bustillo se encargó de recaudar limosnas que diversos fieles dejaban a la Compañía de Jesús para evangelizar las islas Marianas, no sin dificultades. Este fue el caso de Diego de Salcedo, quien dejó 10.000 pesos de su testamento (1668) para dichas misiones (AGN, Instituciones coloniales, Real Hacienda, Archivo Histórico de Hacienda, Vol. 326, ff. 1683-1896). Sobre este asunto, que revela la importancia de las limosnas y donaciones para el mantenimiento de las misiones, véase LÉvESQUE, History of Micronesia, Vol. 6, 1995, 244-253.

152 ARSI, Filipinas 13, ff. 201-206, citado en LÉVESQue, History of Micronesia, Vol. 6, 1995, 542.

153 Schumacher no descarta que los auxiliares, sin ser catequistas strictu sensu, pudieran haber ejercido esta labor («Blessed Pedro Calungsod, Martyr: An Historian’s Comments on His Philippine Background»).

${ }^{154}$ La solución propuesta por el padre Basilio fue juzgada del todo ridícula por el padre Gayoso. Todos estos escándalos llegaron a oídos del provincial Javier Riquelme, quien le ordenó que lo denunciara por escrito ( «Carta del padre Francisco Gayoso al provincial Javier Riquelme, con fecha en Manila, 13 de septiembre de 1676», LÉVESQUE, History of Micronesia, Vol. 6, 1995, 546-547).

Hispania Sacra, LXIII

128, julio-diciembre 2011, 707-745, ISSN: 0018-215-X 
porque los jesuitas, como intermediarios entre Dios y los fieles, les habían ofrecido la salvación a través de los sacramentos. Esto creó una relación de falsa reciprocidad con respecto a sus padres, quienes no acabaron de aceptar que los misioneros se llevaran a sus hijas para saldar la deuda contraída con ellos. Los intercambios de regalos eran signos importantes de reciprocidad -y por tanto, de amistad- entre los pueblos orientales. ${ }^{155}$ Pero como señala Annette Weiner (1992), la preservación de las diferencias entre los samoanos de Melanesia exigía restringir la circulación o control de determinados objetos simbólicos -conchas, collares, etc.- que formaban parte de su identidad social. Los intercambios no estaban determinados por las formas de prestación (Malinowski, Mauss) como por la naturaleza particular de los objetos. ${ }^{156}$ En el caso de la sociedad mariana, no se trataba tanto de objetos físicos como de las prácticas sociales -por ejemplo, servicios sexuales- que se tejían alrededor de las mujeres, las cuales eran indispensables en la reproducción simbólica de su identidad como grupo.

Los marianos eran mayormente monógamos. El matrimonio era libre y no estaba regulado por normas. Las mujeres eran libres para abandonar a sus maridos, pero los jesuitas nunca aceptaron el papel que éstas jugaban en la transmisión de los valores y costumbres de la sociedad chamorra. Para el padre Luis de Morales, este dominio de la mujer sobre el marido era la causa de que infinitud de jóvenes no se quisieran casar. ${ }^{157}$ Estos jóvenes solteros, o urritaos, llevaban a su juicio una vida licenciosa porque tenían la costumbre de alquilar o comprar mujeres para servicios sexuales en una especie de prostitución institucionalizada que había horrorizado a San Vítores. ${ }^{158} \mathrm{Al}$ arrebatarles a sus hijas, o rajaos, los colegios fueron percibidos como lugares donde los «brujos jesuitas» pensaban robarles su fuerza vital y canibalizarlas. Los marianos, como pueblos matrilineales, no debieron encajar demasiado bien la actitud de los jesuitas de llevarse aquellas «posesiones inalienables», que diría Weiner, especialmente si se producía dentro del presidio, lo que aumentaba el recelo de los marianos. Para ellos no había ninguna duda: los padres eran los devoradores de las almas (anitis) de sus abuelos. Ahora, pensaban, los más pequeños eran su objetivo. Por esta razón, el 9 de diciembre de

155 En sus estudios sobre los kwakiutl del noroeste del Canadá, Marcel MAUss sugirió que el don era una estructura potencialmente violenta ya que negarse a participar en el ciclo de las prestaciones y contraprestaciones podía ser interpretado como una ofensa personal (M. MAuss, «Essai sur le don: forme et raison de l'échange dans les sociétés archaïques». Année Sociologique 1 (1925) 30-186).

156 Annete WeIner, Inalienable Possessions: the Paradox of Keeping-while-giving. Berkeley: California UP, 1992. Para un análisis de las tesis de Weiner acerca de la cuestión de la «inalienabilidad» de los objetos, véase Nicholas Thomas, Entangled Objects. Exchange, Material Culture, and Colonialism in the Pacific, London \& Cambridge: Harvard UP, 1991, 22-27.

${ }^{157}$ Luis de Morales, Historia, f. 35.

158 Ibidem, ff. 35; 58; 127. Al respecto, véase ScHUMACHER, «Blessed Pedro Calungsod, Martyr: An Historian's Comments on His Philippine Background», 324. 
1675 varios marianos asaltaron y mataron al hermano Pedro Díaz, ${ }^{159}$ que hablaba muy bien su lengua, junto con los auxiliares -y probablemente soldados- Ildefonso de León y Nicolás de Espinosa, quienes desde finales de 1673 se encargaban de su educación en el pueblo de Ritidian. ${ }^{160}$

De la primera misión a las Marianas (1668-1672), más de la mitad de los jesuitas fueron mártires, víctimas de los ataques furtivos de los nativos que pretendían evangelizar. De la segunda (1674), además del hermano coadjutor Pedro Díaz, ${ }^{161}$ el 17 de enero de 1676 fue asesinado el padre siciliano Antonio María de San Basilio (1644-1676) ${ }^{162}$ por un «indio traidor» del pueblo de Upí, de nombre Quenado, ayudado por su hijo. Le golpearon la cabeza hasta matarlo. ${ }^{163}$

La conciencia de martirio aparece claramente en diversas cartas ológrafas escritas por los misioneros jesuitas. La primera, con fecha en Manila, 10 de mayo de 1675, fue escrita por el padre Pedro Coomans al General Juan Pablo Oliva para que se permitiera dar culto a los mártires de las Marianas con el fin de incitar a la piedad. La segunda, con fecha en el navío «San Antonio de Papua», 14 de mayo de 1676, fue redactada por el padre Lorenzo Bustillos a la duquesa de Aveiro (1630-1715) en la que le agradecía sus esfuerzos y los de su marido, el gobernador y capitán general de las Filipinas, don Manuel Ponce de León, duque de Arcos (1669-77), para enviar cinco nuevos misioneros «a sus propias expensas». ${ }^{164}$ El padre Bustillos, formado como sacerdote en Manila,

${ }^{159}$ El hermano Díaz nació en 1651 en la localidad de Calero, en Talavera de la Reina. Entró en la Compañía de Jesús el 24 de abril de 1673 en el colegio de Oropesa (AHCJC, Carpeta «EI.b-9/5/4. «Mártires de la Provincia de Filipinas de la Compañía de Jesús. Manila, 12 de mayo de 1903», contenida en EI/b-9/5/1-7. «Martirios y varones ilustres». Archivo Provincial de los Jesuitas de Cataluña. Véase también la carta que escribió el padre Gerardo Bowens al General Juan Pablo Oliva (1676) (ARSI, Litterae Annuae Philipp. 1663-1734 (etiam de Insuli Marianis), Tomo 13, f. 129r; ARSI, «Primus Catalogus Anni Personarum Anni 1675». Philippinae Cat. Trien. 1649-1696, Tomo 2-II, f. 395r). Más información en DE la Costa, The Jesuits in the Philippines..., 457; Murillo Velarde, Historia de la provincia de Filipinas, ff. 336r-337v.

160 «Carta del padre Francisco Gayoso al provincial Javier Riquelme, con fecha en Manila, 13 de septiembre de 1676» (LÉvesque, History of Micronesia, Vol. 6, 1995, 552-553); Luis de Morales, Historia, ff. 126-127.

${ }^{161}$ El hermano Pedro Díaz nació en Calero en 1651. Entró en la Compañía de Jesús el 21 de abril de 1673. Era operario de indios en las islas Marianas (ARSI, «Primus Catalogus Anni Personarum Anni 1675». Philippinae Cat. Trien. 1649-1696, Tomo 2-II, f. 395r).

162 El padre Antonio de San Basilio nació en Catania en 1643. Entró en la Compañía de Jesús el 11 de enero de 1659. Era operario de indios en las islas Marianas (ARSI, «Primus Catalogus Anni Personarum Anni 1675». Philippinae Cat. Trien. 1649-1696, Tomo 2-II, f. 392r).

163 Luis de Morales, Historia, ff. 133-134. Sobre una pequeña semblanza de su vida, véase la carta que escribió Lorenzo Bustillos al General Juan Pablo Oliva, con fecha 17 de enero de 1676, en la que le comunicaba la triste muerte del jesuita (ARSI, Philippin. Necrologia 1605-1731, Tomo 20, ff. 312r-314v). Véase también Murillo Velarde, Historia, f. 337v.

164 «Carta del padre Bustillo a la duquesa de Aveiro a bordo del galeón San Antonio de Padua, 14 de mayo de 1676» (LÉVESQue, History of Micronesia, Vol. 6, 1995, 499).

Hispania Sacra, LXIII

128, julio-diciembre 2011, 707-745, ISSN: 0018-215-X 
volvía a las Marianas en la nao «San Antonio de Padua». En esta carta relataba las muertes del padre Luis de Medina (1670), del padre fundador de la misión, Diego Luis de San Vítores (1672) y la del padre Francisco Ezquerra (1674). ${ }^{165}$

Pero hubo más mártires. El 6 de septiembre de 1676, el padre andaluz Sebastián de Monroy (1649-1676) ${ }^{166}$ fue martirizado a lanzadas y machetazos en el mar, a los 28 años de edad, junto con siete soldados que tenía asignados, víctima de una emboscada. ${ }^{167}$ En una pequeña isla apartada de Guam, Monroy empezó a aprender la lengua chamorra, fijando su residencia en el pueblo de Orote. Uno de los soldados que lo acompañaban trató de casarse con una joven recién bautizada. ${ }^{168}$ Los parientes de la doncella se opusieron, supuestamente, por haberse hecho cristiana. Eso encendió los ánimos. Para su biógrafo, el jesuita Gabriel de Aranda, ${ }^{169}$ las conductas de los marianos se definían por la ausencia de orden, policía y moralidad. Su temperamento duro y violento se asimilaba al medio natural hostil, controlado y dominado por ellos, y que los españoles aspiraban a transformar en un espacio civilizado. ${ }^{170}$

Pero la explicación es otra bien distinta. Los religiosos no consintieron las relaciones prematrimoniales de los marianos, basadas en un matrimonio «de prueba» de los jóvenes urritaos, ni tampoco entendieron los aspectos económicos que conllevaba la unión matrimonial, como las prestaciones de trabajo que el pretendiente debía realizar para la familia de la novia durante cierto tiempo, así como el intercambio de regalos (chenchuli). ${ }^{171}$ No hubo dote matrimonial, y

165 Charles Ralph Boxer, «Two Jesuit letters on the Mariana Mission, written to the Duchess of Aveiro (1676 and 1689)», Philippine Studies 26 (1978) 37-42.

166 El padre Sebastián de Monroy nació en 1649. Entró en la Compañía de Jesús en mayo de 1672. Era operario de indios en las islas Marianas (ARSI, «Primus Catalogus Anni Personarum Anni 1675». Philippinae Cat. Trien. 1649-1696, Tomo 2-II, f. 395r).

${ }_{167}$ AHCJC, «Martirios y varones ilustres». Carpeta «EI.b-9/5/2. Martirios, naufragios, \&.», contenida en EI/b-9/5/1-7. Hojas sueltas). Véase también Astrain, Historia, Tomo VI, 824.

168 Desconocemos los hechos, aunque no debería extrañarnos que el soldado en cuestión hubiera forzado a dicha mujer. Un hecho nada ajeno a las prácticas de la época. En 1690, el padre Lorenzo Bustillo confirma que varias mujeres (casadas, solteras) de los partidos de Agaña y Umatac eran sistemáticamente «solicitadas» por soldados. Muchas se resistían, y en reconocimiento a su actitud, fueron aceptadas como congregantes del Santísimo Nombre de María («Relación del estado y progresos de la misión y cristiandad de las islas Marianas desde mayo de 1690 hasta 1691». AHCJC, Documentos Manuscritos Historia de las Filipinas (FILPAS), $\mathrm{n}^{\circ}$ 64, ff. 55v-55r). Sobre la muerte de Monroy, véase también la carta que escribió el padre Gerardo Bowens, con fecha en Agaña, 6 de septiembre de 1676 (ARSI, Philippin. Necrologia 1605-1731, Tomo 20, ff. 316r-321v).

${ }^{169}$ Gabriel de ARANDA, SJ, Vida, y gloriosa muerte del padre Sebastián de Monroy. Religioso de la Compañía de Jesús, que murió dilatando la fe alanceado de los bárbaros en las islas Marianas (Sevi1la, 1690).

${ }^{170}$ GIUdiCELLI, «Pacificación y construcción...», 165.

${ }^{171}$ LedeSma, «Noticias de los progresos de nuestra Santa Fe...», ff. 4r-4v. Véase también THOMPSON, «The Native Culture of the Marianas Islands», 16-18; THOMPSON, Guam and its People, Wesport, Connecticut: Greenwood Press, Publishers, [1947] 1969, 262-265. 
en su lugar, los españoles impusieron nuevas reglas basadas en el sacramento del matrimonio.

Podría decirse, recordando las palabras de Claude Levi-Strauss, que aquella transacción fracasada acabó provocando una guerra entre las dos partes. Y así fue. Una milicia de soldados, liderados por el nuevo gobernador Francisco Irisarri y Vivar (1676-78), hizo entrada en la región, quemando casas y ahorcando al padre de la «novia». ${ }^{172} \mathrm{La}$ aplicación del terror combinado con el asesinato indiscriminado de personas obligó a Monroy y a sus hombres a abandonar la isla, perseguidos por aquellos «bárbaros fronterizos». Por el contrario, el hagiógrafo Aranda (1690) atribuyó siempre la responsabilidad de las hostilidades a la intransigencia de los «licenciosos» urritaos a que se produjera dicho matrimonio. Lo que «había sucedido» (verdad histórica) no era tan importante como situar al personaje en un espacio y tiempo sagrados (verdad hagiográfica o «retórica») ${ }^{173}$. Como las demás hagiografías martiriales, ${ }^{174}$ la de Aranda, inspirada en las relaciones de algunos padres, como Gerardo Bowens (1677) o Pedro de Ahumada (1677), contó también con la participación de un indio traidor responsable de la muerte de los jesuitas. De la misma forma que el padre Florencia (1673, ff. 24r; 30v) culpaba a un tal Choco de difundir entre los marianos que los niños se morían a causa del agua del bautismo, el padre García responsabilizó a los «impíos y sacrílegos» Matapang y Hurao de la muerte del padre San Vítores. En este caso fueron dos indios «malos»: uno, llamado Aguarín, «gran ministro de Satanás», quien, como otro Caín, soliviantó a los pueblos colindantes y los animó a seguir las costumbres de sus antepasados. ${ }^{175} \mathrm{El}$ otro era un indio principal del pueblo de Sumay, de nombre Cheref, quien como «gran traidor», volcó la balsa en la que huían Monroy y los ocho soldados que lo acompañaban, impidiendo así que regresaran a Agaña, siendo martirizados a palos y lanzadas en la playa el 6 de septiembre de 1676.176

172 El navarro Irisarri fue el primero que ostentó el título de gobernador interino. Llegó un miércoles, 2 de junio de 1676 a bordo del galeón «San Antonio de Padua», acompañado de cinco jesuitas (cuatro sacerdotes y un hermano) y setenta y cuatro soldados para el presidio. Aunque era entendido en asuntos de guerra, «acabó de poner las cosas peor de lo que estaban», en palabras del padre Luis de MORALES, provocando nuevas rebeliones entre los marianos («Carta Anua de 1676-1677», LÉVESQUE, History of Micronesia, Vol. 6, 1995, 588-593; Luis de Morales, Historia, ff. 137-138).

173 DURÁn, Retóricas de la santidad, 108.

${ }^{174}$ Florencia, Ejemplar vida y dichosa muerte..., 1673; GarCía, Vida y Martirio del Venerable padre Diego Luis de Sanvitores..., 1683.

175 Luis de MoRALES, Historia, ff. 138-139.

${ }_{176} \mathrm{Al}$ respecto, véase el obituario del padre Monroy escrito por el padre Bowens (RAH, 9/2677, citado en Lévesque, History of Micronesia, Vol. 6, 1995, 360-366); Luis de Morales, Historia, ff. 145146. Más información en ARAnda, 1690, citado en Astrain, Historia, Tomo VI, 824-826; Murillo VELARDE, Historia, ff. 339r-340r. 
Paralelamente, un grupo de quinientos marianos, liderados por Diego Aguarin, atacaron a los españoles por sorpresa en Agaña. Los mantuvieron reducidos en la iglesia y en las casas aledañas, pero la superioridad del armamento hispano acabó imponiéndose. Los españoles castigaron severamente a los revoltosos, aunque el cabecilla Aguarin consiguió huir. Ante esta escalada de violencia, la reacción no se hizo esperar. El capitán Esplana envió a veinte soldados a Umatac a levantar una empalizada o «castillo de madera» para protegerse de los ataques enemigos. ${ }^{177}$ Poco después partió a Manila (junio, 1676) en el galeón «San Antonio de Padua» acompañado del padre Francisco Gayoso y varios soldados mientras que el primer gobernador de las islas, don Francisco de Irisarri y Vivar (1676-78), junto con setenta y cuatro soldados españoles, se sintió legitimado a hacer la «guerra justa» a los marianos sublevados (septiembre, 1676-marzo, 1677). ${ }^{178}$ Pero lo cierto es que los misioneros necesitaban estos «bárbaros» para justificar su presencia en las islas. Representaban la cara oculta de una realidad -la del «indio bueno y leal»-que todavía no había recibido la luz del evangelio. Ello no representaba una contradicción, sino que constituía una parte inherente al discurso martirial. ${ }^{179}$ Un triunfo del bien sobre el mal que legalizó la posesión española de las Marianas al haber sido «regada con la sangre de sus mártires». ${ }^{180}$ Fue el inicio de una relación hostil que se extendió a las islas del Norte, ampliando el radio de acción del mesianismo jesuítico.

\section{EPÍlOGO: LA DIÁSPORA DE LOS CUERPOS}

Los héroes no se definen por sus gestas, sino por la difusión de la leyenda de sus hazañas. Las cartas o biografías de aquellos misioneros son pequeñas narrativas de martirio y muerte cuyo objetivo era edificar a los fieles. En todas ellas existe una autopercepción de un «nosotros-jesuítico» que se enfrenta a los «otros-paganos» en un territorio fronterizo.

Los nativos fueron vistos como enemigos a partir de la consagración del territorio cristiano que había que proteger. Los informes de los jesuitas no dejan

177 En 1676 el presidio tenía destacados a noventa soldados con su capitán. Al respecto, véase la «Relación de la derrota del padre Francisco Gayoso (1674-76) de la Compañía de Jesús desde las islas Marianas a las Filipinas año 1676 sacada de una carta que escribió al padre Javier Riquelme provincial de la Compañía en las Filipinas» (ARSI, Litterae Annuae Philipp. 1663-1734 (etiam de Insuli Marianis), Tomo 13, ff. 133r).

178 Luis de MoRALES, Historia, ff. 136-137.

179 Vicente M. DíAZ, Repositioning the Missionary: the Beatification of Blessed Diego Luis de Sanvitores and Chamorro Cultural History. Tesis Doctoral. University of California - Santa Cruz, 1992, 30 .

${ }^{180}$ La expresión corresponde al padre superior Pedro Coomans en una carta que escribió al padre Van Schoonen, con fecha en Manila, 20 de mayo de 1675 (LÉvESQuE, History of Micronesia, Vol. 6, 1995, 282). 
ninguna duda. Son «bárbaros», que golpean, hieren, asesinan a los jesuitas y a sus ayudantes, y después de martirizarlos, los arrojan al mar, en un acto simbólico de expulsión de las islas. En 1674, Francisco Ezquerra murió junto con cinco de sus compañeros auxiliares, Sebastián de Ribera, Luis de Vera Picazo, de Manila, Pedro de Alejo y Marcos de Segura, de Puebla de los Ángeles, y Matías Altamirano, de Oaxaca. El sexto, Francisco González, sobrevivió de las heridas y certificó la veracidad de los hechos al padre Pedro Montes, rector de Silung. ${ }^{181}$ Como testigos de Dios, sufrieron martirio. Los jesuitas, como apóstoles de Cristo, no excluían en su misión la tragedia de la sangre.

Para los reformistas católicos, el martirio se vinculaba a la exaltación de la libertad, a la existencia de una fe única e indivisa, de una fe sin fisuras, a la cual se daba hasta la muerte. Emular al «rey de los mártires» implicaba no sólo transmitir su palabra, sino aceptar con paciencia la persecución y el sacrificio de la propia vida por la fe. ${ }^{182}$ Cuantos más duros son los tormentos infligidos o soportados, más merecían entrar en la categoría de mártir. La muerte en el púlpito, la cárcel, o al servicio de la iglesia constituían formas diversas de oponerse heroicamente a los apóstatas o negadores de la fe.

En las cartas martiriales, el jesuita de las Marianas aparece como soldado de Cristo que lucha denodadamente en su nombre para convertir las islas en un «vivero de flores espirituales».183 No le es lícito huir de sus perseguidores ni de la muerte. Busca, en última instancia, alcanzar la perfección a partir del martirio y del tormento voluntarios como el camino más seguro hacia Dios. Recordemos las llamadas bienaventuranzas: «Si alguno quiere seguirme, niéguese a sí mismo, lleve a cuestas su cruz y sígame. Pues el que quiera salvar su vida, la perderá; pero el que pierda su vida por mí, la encontrará». Una invocación al martirio que refleja claramente una mentalidad heroica, victoriosa, que no se amedrenta ante el peligro y que acepta su destino con resignación. ${ }^{184}$

${ }^{181}$ Luis de MoRAles, Historia, ff. 116-119. Véase también Astrain, Historia, Tomo VI, 822.

182 Gregory, Salvation at Stake, 276-287; Antonio Rubial GarciA, «A imagen y semejanza». La Nouvelle-Espagne dans le miroir apostolique, biblique et paléochrétien», en: Nejma KERMELE \& Bernard LAVALLE (coord.), L'Amérique en projet. Utopies, controverses et réformes dans l'empire espagnol (XVIe - XVIIIe siècle). Paris: L'Harmattan, 2008, 76. Sufrir con paciencia los rigores de la fe era una de las virtudes características de la llamada Devotio Moderna del canciller de la Universidad de París, Jean de Charlier de Gerson (ca. 1363-1429), y sobre todo, del espíritu de la Imitación de Cristo (1425) de Tomás de Kempis (ca. 1380-1471) (Salvation at Stake, 50-62).

183 Sobre la idea de colonización como horticultura espiritual, véase CAÑIZARES-EsGUERRA, Católicos y puritanos..., 264; 239-283.

184 Mateo, 16, 24-25, citado en Ramón TEJA, «Mortis Amor: la muerte voluntaria o la provocación del martirio entre los primeros cristianos (siglos II-IV)», en Francisco MARCo Simón \& Francisco PINA Polo \& José Remesal Rodríguez (eds.), Formae Mortis: el tránsito de la vida a la muerte en las sociedades antiguas. Barcelona: Publicacions de la Universitat de Barcelona, 2009, p. 135.

Hispania Sacra, LXIII

128, julio-diciembre 2011, 707-745, ISSN: 0018-215-X 
La destrucción sistemática de los colegios e iglesias jesuitas, el ensañamiento con objetos e imágenes consagrados al culto, la profanación de la hostia consagrada, las parodias y burlas de los ritos y creencias católicos se explicaban como parte del odio hacia los representantes de Cristo. La iconografía representa fielmente el discurso de violencia en el que se basa el martirologio de numerosos jesuitas, como San Vítores o Sebastián de Monroy, convertidos en los primeros mártires de las Marianas. ${ }^{185}$ Pero la sangre de aquellos mártires galvanizó la sociedad del futuro.

El hecho martirial y su culto generaron una demanda de lo «santo» que aumentó considerablemente después del Concilio de Trento. ${ }^{186}$ El tráfico de «reliquias antiguas» popularizó a los mártires de la cristiandad, pero al mismo tiempo exigió la producción de «nuevas reliquias» como objetos de adoración. ${ }^{187}$ Los restos de sus cuerpos santos debían desmembrarse y disgregarse a diversos lugares como una forma de estructurar el espacio cristiano. ${ }^{188}$ Esta fue una de las razones por las cuales el capitán Juan de Santa Cruz Panday, acompañado de nueve soldados, regresó a Saipán el 24 de abril de 1670, a los tres meses de la muerte del padre Medina, para rescatar «sus benditos huesos» y los del hermano Hipólito de la Cruz. ${ }^{189}$

${ }^{185}$ Las cartas de edificación, como ejemplos del «discurso teatral» que caracterizó al epistolario jesuita, se escribían al poco tiempo de la muerte de los mártires (Inés G. Zupanov, Disputed Mision: Jesuit Experiments and Brahmanical Knowledge in Seventeenth-century India, Oxford \& New York: Oxford UP, 1999). El 14 de mayo de 1671 Diego Luis de San Vítores escribió acerca de la ejemplar vida del padre Luis de Medina (RAH, Fondo Cortes, 567, 9-2676/13, ff. 1r-7v), mientras que el 2 de abril de 1672, poco después de la muerte del superior de la misión, se escribía La Vida del Invicto Soldado de Cristo, el Venerable Padre Diego Luis de San Vitores (RAH, Fondo Cortes, 567, 9-2676/24, ff. 1r-51v), así como un Compendio de las virtudes y milagros del apostólico Padre (RAH, Fondo Cortes, $567,9-2676 / 16$, ff. 1r-32v).

${ }^{186}$ BouZA, Religiosidad contrarreformista..., 42-62.

${ }^{187}$ Las nuevas reliquias no relegaron a las antiguas al olvido. Por el contrario, «the new martyrsaints were not competing with the old. In fact, the renewal of Catholic martyrdom seems to have accentuated, not displaced, the veneration of the early martyr-saints, strengthening the sense of an ancient tradition reborn» (GREGORY, 1999, 306). Para un interesante análisis de las reliquias en tanto mercancías sagradas, véase los trabajos de BouZA, Religiosidad contrarreformista..., 27-29; 47-56; Patrick Geary, Furta Sacra, Thefts of Relics in the Central Middle Ages, New Jersey: Princeton UP, [1978] 1990; GEARY, «Mercancías sagradas: la circulación de las reliquias medievales», en: Arjun Appadurai (eds.), La vida social de las cosas. Perspectiva cultural de las mercancías, México, Grijalbo, 1986, 211-239.

${ }_{188}$ Renato CYMBALISTA, «Relíquias sagradas e a construção do território cristao na idade moderna». Anais do Museu Paulista, 14 (2006), 13; Rubial García, «A imagen y semejanza», 76; Durán, Retóricas de la santidad, 122. Las reliquias pertenecían a la doble categoría de objetos dotados de un componente material -visibles, tangibles-y sobrenatural. Su contacto con los santos los hacían partícipes de la gracia divina (BouZA, Religiosidad contrarreformista..., 42; GEARY, Mercancías sagradas, 211). En el Juicio Final, sin embargo, «Dios volvería a recomponer parte a parte hasta el último pelo y uña los cuerpos de los bendecidos» (CAÑIZAREs-EsGUerRa, Católicos y puritanos..., 127).

189 AHCJC, «Más sobre la vida y martirio del padre Luis de Medina», f. 1. 
No sólo los restos de los jesuitas martirizados, sino incluso las armas con las que fueron sacrificados pasaron a formar parte de lo sagrado.

«Se sacaron en fin las reliquias del dichoso padre las cuales vinieron acompañando los que habían ya concurrido, que serían unos treinta de dicho pueblo de Cao a quienes se llegó también, aunque no muy de su grado, el que había tirado la primera lanza que causó la dichosa muerte del padre y así todos le llamaban absolutamente el matador: este había ido a la primera cita de los nuestros en Beauran, y con tal prisa, que se dejó la lanza en el suelo, la cual cogió uno de nuestros compañeros». ${ }^{190}$

Lo que resulta especialmente significativo del epígrafe anterior es que el capitán Santa Cruz tenía plena conciencia de que los restos mortales del padre Medina no eran simples despojo humanos, sino reliquias que debían tratarse con respeto y deferencia. Existía la creencia compartida de que se trataba de objetos de gran valor simbólico, económico, para los fieles. Al recuperarlas, se esperaba que el «santo» continuara intercediendo por los vivos desde la otra vida. Esta creencia fue alentada por la iglesia para afianzar su poder terrenal. Si los «santos» no morían del todo, sus reliquias elevaban el poder y prestigio de las iglesias que las poseían. ${ }^{191}$

Como apunta Manuela Carneiro da Cunha, estas hierofanías fueron «vehículos de transporte de lugares» a otros consagrados por el cristianismo. ${ }^{192} \mathrm{La}$ veneración de los mártires católicos en Inglaterra y Francia fomentó la demanda de reliquias (monumenta martyrum), las cuales fueron trasladadas a otros colegios e iglesias jesuitas para consagrarlos. ${ }^{193}$ Pero esta distribución de reliquias no se estableció sobre la base de una relación económica, sino a partir del ofrecimiento y recibimiento de obsequios sagrados. 194

190 Juan de SANTA CRUZ, «Vida y martirio del padre Luis de Medina» (AHCJC, Carpeta de mártires - EI.b-9/6, f. 3). Existe un traslado de esta carta martirial en AHCJC, Historia Missionis, Tomo III, y titulado «Copia de documentos antiguos del Archivo de la Misión de la Compañía de Jesús, $\mathrm{n}^{\circ}$ 1», Signatura Antigua: E.I.,a-13 (1593-1890), ff. 604-615.

191 GeARY, Mercancías sagradas, 219; Fernando MARTínez GIL, «Religión e identidad urbana en el arzobispado de Toledo (siglos XVI-XVII)», en J. Carlos Vizuete Mendoza \& Palma Martínez-BuRGOS GARCíA (coord.), Religiosidad popular y modelos de identidad en España y América, Cuenca: Ediciones de la Universidad Castilla-La Mancha, 2000, 38-39.

192 Citado en Renato CyMBALISTA, «Relíquias sagradas e a construção...», 26. Al respecto, véase también Pierre-Antoine FABRE, «Reliquias romanas en México (1578): historia de una migración». Ponencia presentada en la Mesa Redonda 3: Reliquias, sacramentos y objetos sagrados correspondiente a las XII Jornadas Internacionales de Misiones Jesuíticas (23 al 26/09/2008), «Interacciones y sentidos de la conversión», 2008.

193 Por ejemplo, las reliquias de Edmund Campion, las cuales fueron enviadas al Colegio Inglés, de Roma, donde los jesuitas se preparaban para recibir martirio en Inglaterra (GREGORY, Salvation at Stake, 298-314).

194 GeARY, Mercancías sagradas, 226-228. Siguiendo los trabajos de Marcel Mauss (Essai sur le don, 1922), la prestación y contraprestación de bienes creaba vínculos, o alianzas, entre el dador y el recibidor que trascendían los bienes materiales (Mercancías sagradas, 215-217).

Hispania Sacra, LXIII

128, julio-diciembre 2011, 707-745, ISSN: 0018-215-X 
Existen datos que confirman la rapidez con que dichos regalos alcanzaron la península ibérica. Según la opinión del padre Luis de Morales, algunos de sus cofrades, como el padre Francisco Herrera, poseían reliquias del padre San Vítores cuyos poderes curativos eran utilizados para curar enfermedades en casos de extrema necesidad. Así,

«Este mismo padre, habiendo sido llamado para asistir en su muerte a doña Beatriz de Tascos que vivía cerca de la ciudad de Badajoz, en España, encontró a esta señora desahuciada de los médicos, recibidos todos los sacramentos y próxima a espirar. Le aplicó una reliquia del Siervo de Dios de la cual había experimentado él mismo los efectos exhortándola a encomendarse al padre San Vítores a fin de recobrar la salud por medio de su intercesión. Ella lo hizo llena de confianza y desde aquel momento notó que mejoraba hallándose al cabo de algunos días completamente buena, lo cual don Jacinto Lobato, médico mayor del ejército de Extremadura, cuya habilidad y fama era conocida de todos, afirmó no poder verificarse sin milagro».195

La ocupación territorial de las Filipinas, y por ende, de las Marianas, no estuvo al margen de esta capitalización del hecho martirial. La producción y distribución de aquellas reliquias presuponía la incorporación de aquellas tierras al espacio y tiempo cristianos. ${ }^{196}$ Así, tras el asesinato del padre Medina, muchos de sus cofrades trataron de imitar su muerte. La recuperación del cadáver del nuevo San Sebastián y la del arma homicida ilustra un episodio heroico y su transmutación en objetos sagrados. No se trataba simplemente de un cuerpo muerto, sino de una obra viva penetrada por la razón a través de la luz celestial. Huesos, uñas, carnes despegadas de sus almas pasaban a ser posesión de los fieles, quienes esperaban invocar sus poderes taumatúrgicos para protegerse de todos sus males. ${ }^{197}$ A diferencia de los objetos mágicos de los idólatras, aquellas almas desarticuladas de sus cuerpos representaban, como diría Fabre (2008), la tragedia del triunfo de los santos. Una victoria simbólica que se erigía sobre una sociedad que se resistía a doblegarse al imperio español.

195 Luis de MoralEs, Historia, ff. 100-101.

${ }^{196}$ CYMBALISTA, «Relíquias sagradas e a construção...», 42.

197 GREGORY, Salvation at Stake, 307-314. 